Discussion

Papers
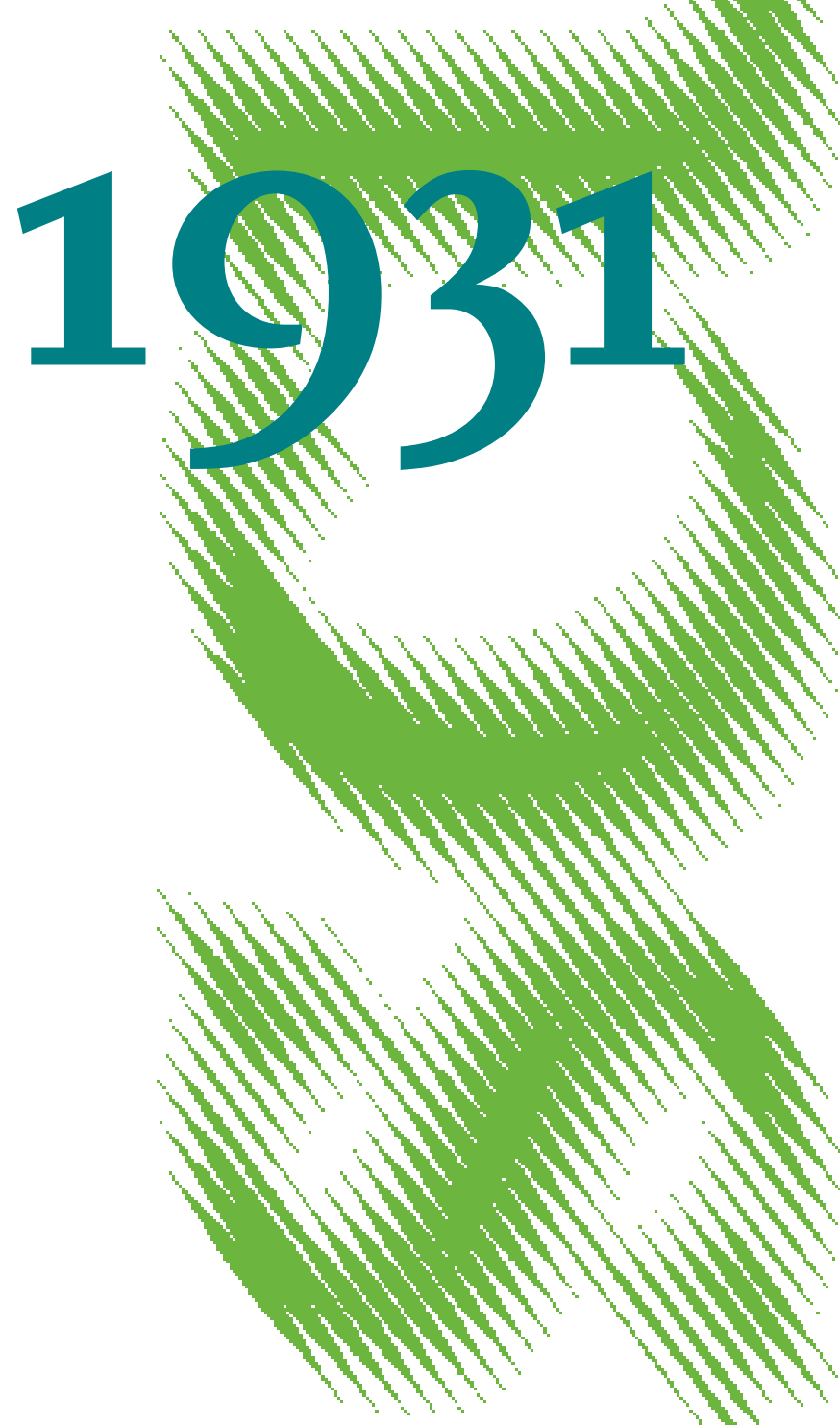

A Retrospective Study of State Aid Control in the German Broadband Market 
Opinions expressed in this paper are those of the author(s) and do not necessarily reflect views of the institute.

IMPRESSUM

(C) DIW Berlin, 2021

DIW Berlin

German Institute for Economic Research

Mohrenstr. 58

10117 Berlin

Tel. +49 (30) $89789-0$

Fax +49 (30) $89789-200$

http://www.diw.de

ISSN electronic edition 1619-4535

Papers can be downloaded free of charge from the DIW Berlin website:

http://www.diw.de/discussionpapers

Discussion Papers of DIW Berlin are indexed in RePEc and SSRN:

http://ideas.repec.org/s/diw/diwwpp.html

http://www.ssrn.com/link/DIW-Berlin-German-Inst-Econ-Res.html 


\title{
A Retrospective Study of State Aid Control in the German Broadband Market*
}

\author{
Tomaso Duso ${ }^{\dagger}$ Mattia Nardotto $\ddagger$ and Jo Seldeslachts ${ }^{\S}$
}

February 5, 2021

\begin{abstract}
We provide an evaluation of the impact of public subsidy schemes that aimed to support the development of basic broadband infrastructure in rural areas of Germany. Such subsidies are subject to state aid control by the European Commission (EC). While the EC increasingly recognises the role of economic analysis in controlling public aid to companies, there are to date no full retrospective studies performed on state aid control, especially assessing the so-called balancing test. In this study, we do not only analyse whether the aid was effective in solving a market failure - low broadband coverage in rural areas - but also study its impact on competitive outcomes, on both rival firms and consumers. We adopt a difference-in-differences framework after using a matching procedure to account for selection on observables. We find that the aid significantly increased broadband coverage. More importantly, we find that the number of internet providers has significantly increased in the municipalities receiving aid. This additional entry decreased average prices. Therefore, the subsidies complied with EU state aid rules, both in terms of effectiveness and competition.
\end{abstract}

Keywords:State Aid, Ex-Post Evaluation, Broadband, Coverage, Entry, Competition, Prices. JEL Codes: C23, D22, L1, L4, L64

\footnotetext{
*This paper is partially based on a research project we undertook for the Directorate General Competition (DG Competition) of the European Commission. We thank the DG Competition's staff for their support during the course of this study, in particular Adriaan Dierx, Fabienne Ilzkovitz, and Luca Marziale. We also thank Ivan Mitkov and Julian Hidalgo for their excellent research assistance, as well as Jesus Crespo Cuaresma, Klaus Gugler, Harald Oberhofer, Florian Szuecs, Otto Toivanen, Tommaso Valletti, Matthew Weinberg, Christine Zulehner; seminar participants at DIW Berlin, CCRED Johannesburg, KU Leuven, MINES ParisTech, WU Vienna, and conference participants at CRESSE, CESifo, JEI, and EARIE conferences for helpful comments and suggestions. Tomaso Duso gratefully acknowledges support from the Berlin Centre for Consumer Policies (BCCP). Jo Seldeslachts gratefully acknowledges support from the Flemish Science Foundation (FWO).

${ }^{\dagger}$ Deutsches Institut für Wirtschaftsforschung (DIW Berlin), Technische Universität Berlin, CEPR, and CESifo. E-mail: tduso@diw.de.

$¥$ Corresponding author. KU Leuven, and CESifo. E-mail: mattia.nardotto@kuleuven.be.

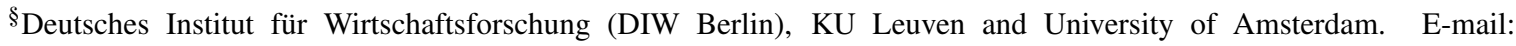
jseldeslachts@diw.de.
} 


\section{Introduction}

Given the importance of information and communication technology (ICT) in modern economies (e.g. Czernich et al., 2011; Akerman, Gaarder and Mogstad, 2015), developing a modern internet infrastructure is a priority for countries in the European Uniuon (EU) and the core of the "Digital Agenda for Europe" (DAE) 1 Yet, the fixed costs required to set up a telecommunication network are sizable. For the most costly technology, fiber to the home (FTTH), a recent study by the European FTTH Council estimates the cost to complete the coverage in the EU28 countries to be $€ 137 \mathrm{bn}$ (FTTHCouncil, 2017). Given the large amount of fixed costs, telecom operators are reluctant to roll out up to date technologies in places where the expected demand for internet services is not sufficiently high, such as rural areas (Greenstein, 2020) 2 Thus, most EU countries are allocating large amounts of public resources with two goals. First, to sustain investment in new infrastructure and, secondly, to ensure that areas otherwise less attractive to internet service providers do not fall behind.

In principle, subsidies by national governments to companies, i.e., "state aid," are forbidden by the EU treaty because they are likely to distort competition and adversely affect trade. However, the EU rules recognise that state aid, in general, and broadband, in particular, can contribute to economic development ${ }_{3}^{3}$ For this reason, the European Commission (EC) has the power to approve certain types of aid measures. As specified in Article 107 of the Treaty on the Functioning of the European Union (TFEU), state aid is allowed by the EC if it passes the so-called balancing test, where the beneficial effects of state aid are weighted against their potential adverse effects on competition and trade. In particular, state aid is allowed in the EU when (i) it is well designed to appropriately solve the market failure, and (ii) distortions to competition are limited so that the overall balance is positive (see GómezBarroso and Feijóo, 2012, for a detailed exposition of the balancing act in the context of broadband state aid).

Traditionally, this balancing test is performed ex-ante, with little economic analysis (Munoz de Juan (2018)). But the EC increasingly recognises the role of an ex-post economic analysis in controlling public aid. Indeed, the EU's State Aid Modernisation (SAM) initiative by the Directorate General of Competition (DG Competition) in 2014 introduced the obligation for retrospective evaluations of aid schemes (Friederiszick et al., 2018). This obligation has kickstarted a literature on the retrospective evaluations of different types of state aid, mainly in the areas of R\&D subsidies (e.g. Szücs, 2020, and references therein) and regional aid (e.g. Becker, Egger and von Ehrlich, 2018, and references therein).

In this context, however, it is surprising that no retrospective studies fully assessing the balancing test exist as of today. Indeed, while many studies look at the impact of subsidies on those outcomes

\footnotetext{
${ }^{1}$ Communication from the Commission to the European Parliament, the Council, the European Economic and Social Committee and the Committee of the Regions, COM(2010) 245 final, A Digital Agenda for Europe.

${ }^{2}$ Indeed, there is often a large gap between social and private incentives to invest in telecom infrastructure, as Nevo, Turner and Williams (2016) find for US broadband markets.

${ }^{3}$ See, for example, Criscuolo et al. (2019) for the impact of state aid on employment of broad regional aid and Briglauer et al. (2019) for an application of the impact of broadband deployment in Germany on employment.
} 
that measure the identified market failure, there is, to the best of our knowledge, no study investigating the impact of state aid on competition 4 The aim of the current paper is to fill this gap. The underlying idea is to make a start at bringing the evaluation of state aid control more into line with experiences in other areas of competition policy, such as merger control and abuse of dominance, where competitive assessments are at the core (Robins and Geldof, 2018) 5

We investigate the impact of a national subsidy scheme in Germany that was announced in 2008, as well as subsequent regional programs in Bavaria and Lower Saxony in 2009 and 2010. These schemes, implemented between 2011 and 2013, sought to support the development of basic broadband infrastructure in rural areas and obtained approval from the EC. Our analysis aims at evaluating the effect of these aid schemes on broadband availability - the outcome measuring the market failure - as well as their impact on competition, specifically with respect to the number of competitors as well as prices.

We look at different measures of competition since there are multiple ways to characterise the potential distortions of product market competition in the area of state aid in terms of theory of harm, as suggested by Verouden and Stehmann in Flynn (2016). We first look at whether the subsidies did no harm to rivals, as this is the traditional dimension of competition used in state aid control in those rare cases where the EC has looked into this issue (Heidhues and Nitsche, 2006). Specifically, we evaluate the impact of the aid on the number of active internet service providers (ISPs) in each municipality, with the logic that if the number of providers did not decrease after the aid, then this surely cannot have harmed rivals. However, there is a strong case to be made to further look at consumer welfare, as this is a much better defined concept and as it is the welfare standard adopted in other areas of competition policy (see Nitsche, Heidhues et al. 2006, for an extensive discussion). Therefore, in a second instance, we look at how the change in market structure induced by the aid affected consumer prices.

We collect and merge data from several sources and create a database that covers a panel of virtually all municipalities in Bavaria and Lower Saxony between 2005 and 2015. The database contains information on key variables of the broadband internet market: broadband coverage (at different download speeds), number of ISPs, and prices of broadband plans. We complement this data with information on the subsidies allocated to the municipalities and with other key factors driving investment decisions at the local level, such as socio-demographic characteristics, industrial presence, and geographical characteristics.

We adopt a difference-in-differences (DiD) methodology that compares the evolution of our outcome variables -broadband coverage, number of firms, and effective prices- in municipalities that

${ }^{4}$ There are papers that look at the effect of state aid on related outcomes, such as the financial viability of firms (Heim et al. 2017), firms' growth (Cerqua and Pellegrini] 2014), or firms' productivity (Sergant and Van Cayseele 2019) and (Criscuolo et al. 2019).

${ }^{5}$ Although Verouden and Stehmann argue in Flynn (2016) that perhaps applying a more economic approach to state aid should not be understood as making it fully equal to antitrust or merger control. Indeed, it is often not possible to weigh state aid's benefits (such as regional cohesion) against its costs (such as distorting competition). However, in our setting, one can make a precise assessment of both benefits and costs. 
implemented the aid to the outcomes in municipalities that did not make use of the schemes. We compare 2010, the year before the projects effectively started to be implemented ("pre-treatment period"), and 2015, which is two years after all projects were concluded ("post-treatment period"). Furthermore, as the allocation of the aid was not a random treatment, we perform a preliminary step aiming at eliminating selection bias due to observed characteristics. Hence, we match each aid-implementing municipality to a comparable municipality in terms of demographic and technological features through a procedure based on propensity score matching. As such, our paper is situated in the literature that aims to provide evidence on a causal link between policy and outcomes, by exploiting regional variation (for excellent examples, see Criscuolo et al., 2019; Kline and Moretti, 2014a b).

We show that the aid schemes were successful in fostering broadband development in the targeted areas, as they were effective in increasing coverage within the aid-implementing municipalities. Specifically, we measure an additional increase in broadband coverage due to the aid ranging between almost $14 \%$ to over $20 \%$ (depending on the connection speed), in line with the findings of Briglauer et al. (2019). From these results, our back-of-the-envelope calculations show a cost per potentially connected household at $2 \mathrm{Mbit} / \mathrm{s}$ of ca. $€ 235$. Our findings also suggest that aid-implementing municipalities sped up three to four years in broadband development when compared to the control municipalities.

Moreover, and this is the most important and novel contribution of our study, we find that the implemented schemes did not distort competition. On the contrary, first, we discover that the number of ISPs significantly increased in the treated municipalities when compared to the control group by ca. 10\% between 2010 and 2015. Second, we find a small but significant negative impact on prices and that this downward pressure on prices is directly caused by the increased entry. Interestingly, price decreases are more pronounced when entry occurs in initially more concentrated markets, in line with the findings for the US by Xiao and Orazem (2011), 6 Thus, our general findings are that industrial policy, competition, and consumer welfare can go hand in hand 7

We provide several extensions and robustness checks. First, we allow for spatial correlation among neighbouring municipalities applying for aid and show that the results are robust to allowing spatially correlated errors. Second, we look at whether different amounts of aid have had a differential impact. We find that the highest marginal effect of the aid is generally observed for medium-sized grants, which indicates that there is an optimal subsidy amount. Third, when looking at yearly effects -instead of the main before-after analysis- we find that the aid was effective immediately in terms of increasing

\footnotetext{
${ }^{6}$ In a related study, Nardotto, Valletti and Verboven (2015) show that market entry induced by local loop unbundling had the effect of fostering both product differentiation and large quality improvements in the UK's fixed broadband market. Another relevant paper in our context is Fan and Xiao (2015), which studies various subsidy policies designed to encourage entry. They estimate a dynamic entry game based on data of actual and potential entrants after the 1996 Telecommunications Act, which opened the monopolistic US local telephone industry to new entrants. Examples for the positive link between entry -or more generally the number of firms active in a market- and market outcomes is also found for other sectors, including the mobile telecommunication industry (Genakos, Valletti and Verboven 2018), the banking sector (Cohen and Mazzeo, 2007), and the food industry (Toivanen and Waterson. 2005).

Aghion et al. (2015) present similar findings. By using a dataset of medium and large enterprises in China, they show that industrial policies in competitive sectors increase productivity growth, where competition in a sector is defined based on the Lerner Index.
} 
coverage, but that the impact on entry was slower to catch up. Finally, we go beyond average effects and show that there is some degree of heterogeneity in the effectiveness of the aid. Specifically, we find that the aid was most effective where it was most needed: e.g., in municipalities with low coverage pre-aid.

The paper is structured as follows. In Section 2 we provide some background information on the state aid schemes. Section 3 describes the data, while Section 4 shows a first look at the broadband market. We present our econometric model and empirical results in Section 5 . Section 6 shows extensions and robustness checks while 7 concludes.

\section{Broadband in Germany and the state aid schemes}

The evolution of the broadband internet market in Germany is similar to the rest of the EU. At the end of the 1990s, when the first versions of digital subscriber line (DSL) technologies were introduced, the market was dominated by Deutsche Telekom (DT), the formerly state-owned telecommunication company. Following the EU Regulation EC 2887/2000 and the Directive 2002/19/EC, the German government passed the so-called open access policies, which required the incumbent to open the market to entrants, allowing them to provide internet services over DT's network. These policies allowed, like in other EU countries, for a rapid growth of the market share of new ISPs, which competed with DT for internet users accessing the internet through fixed-lines. In the first decade of the 2000s, given that mobile internet technologies were not yet sufficiently developed, the main alternative to DSL access was cable, another fixed-line technology, which had a market share of approximately $10 \%$ at the national level. With the start of the second decade of the 2000s, mobile technologies diffused rapidly, mostly as a complement to fixed-line connections. In the 2010s, the next step of fixed-line internet access - fiber - started, although at relatively slow adoption rate compared to previous technologies.

Figure 1 shows the evolution of broadband penetration over time. Thanks to the large investments made by telecom companies, internet access quickly diffused in the country. However, despite a sustained growth of internet penetration, which went from only $10 \%$ to more that $80 \%$ in just ten years, access to the internet was not uniform. This phenomenon is often referred to as the digital divide, a situation that the OECD (OECD, 2001, p.5) defines as follows: "The gap between individuals, households, businesses and geographic areas at different socio-economic levels with regard both to their opportunities to access information and communication technologies and to their use of the internet for a wide variety of activities" While this statement covers many alternative definitions, the divide targeted by the aid schemes studied in this paper concerns the gap between rural and urban areas.

The difference between rural and urban areas in Germany can be summarised as follows: In 2010, a decade after the introduction of broadband internet, $19 \%$ of municipalities had internet access at a speed of $16 \mathrm{Mibt} / \mathrm{s}$ or higher, but these municipalities accounted for over $40 \%$ of total population, indicating that these are large/densely populated (urban) municipalities. This disproportional coverage 
Figure 1: Broadband penetration in Germany

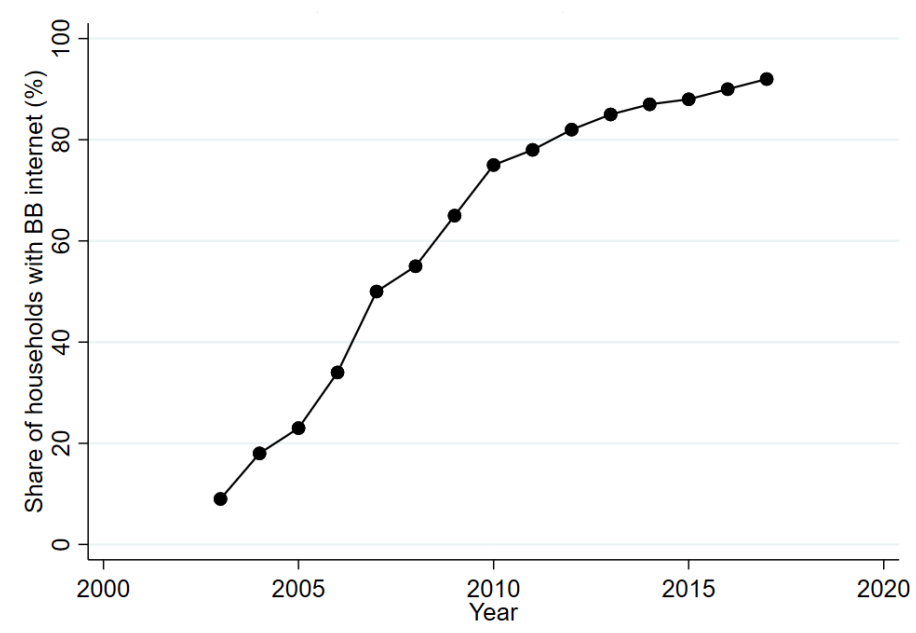

Source: Eurostat

of a minority of municipalities is the result of simple economic trade-offs: urban areas provide stronger incentives for IPSs to undertake the large, fixed investments, thus generating a gap in internet access with rural areas, sometimes to the point of these not having internet access at all. Reducing this gap through investment in rural areas was the goal of the state aid we study.

The main idea behind the aid schemes was to intervene by closing the "profitability gap" in deploying broadband infrastructure, i.e., the difference in investment costs and profitability thresholds, in order to provide similar broadband services in rural areas compared to urban areas. Thus, the aim was to generate the right conditions for private operators to enter -and possibly compete- in rural markets. Regional authorities could apply for the aid and implement the scheme if at least some parts of the region were identified as "white areas," i.e., areas where no provider was offering internet services. Intervention areas were mostly designed at the level of municipalities, which were the implementing authorities; although the ultimate aid recipients were the operators designated as beneficiaries via ten$\operatorname{ders} 8$ The schemes were set up to with the aim to support the construction of basic broadband service networks, later stated in the 2009 broadband guidelines of the EC (European Commission (2009)). An important obligation that was part of the schemes was to allow third parties' wholesale access to a subsidised broadband infrastructure as an indispensable component of any aid given.

We investigate the impact of a national aid scheme, as well as two subsequent regional programs in Bavaria and Lower Saxony; all three projects received approval from the EC. First, scheme N115 was issued in July 2008 and consisted of $€ 141$ million (decision N 115/2008). The aid intensity for each single infrastructure project was related to the profitability gap, initially limited to a maximum

\footnotetext{
${ }^{8}$ We have unfortunately no information on how the tender processes exactly worked and which exact operator was the beneficiary, as this data was not kept in a systematic way by national or local authorities. Therefore, the unit of observation in our analysis is a municipality that obtained aid. In some cases, several municipalities coordinated and jointly applied for the aid; see also our extension where we allow for spatial correlation.
} 
amount of $€ 200,000$ in public funding for each project. As the N115/2008 scheme was not sufficiently employed, the German authorities notified amendments with the schemes N368/2009 and N299/2010 9 The amendments were mainly aimed at modifying some of the rules approved in the previous scheme. Moreover, the maximum amount in public funding was increased to $€ 500,000$ per project.

As an addition to these national schemes, which were mostly aimed to help the deployment of broadband lines for private households, the states of Lower Saxony and Bavaria decided to mobilise additional public funding of around $€ 45$ million to help further reduce the digital gap in their respective regions. These regional schemes were especially focusing on broadband availability for business, and were not expected to be implemented on top of the national scheme; i.e., projects received funding under one scheme only. However, within the same geographical area, several projects were implemented under the various schemes. The actual investment supported by these schemes took place in the following years, mostly from 2012 onwards.

In all three schemes, the Commission took into consideration the potential qualification of the aid as de minimis: small subsidies are supposed to have unsubstantive competitive effects and do not need the approval of the EC ${ }^{10}$ Therefore, each single project financed under a particular scheme would not be considered to be state aid under the EC's rules. However, prolongations and amendments moved the aid amount beyond a de minimis level. Moreover, while the EC approved the schemes, concerns were raised as some ISPs were expected to be awarded aid for several local projects in different municipalities and, therefore, could have received cumulative aid in excess of $€ 200,000$ over 3 years. Nevertheless, the EC ruled that the distortions of competition and the effect on trade were most likely still limited, and, therefore, that the overall impact of the measures was likely to be positive. This paper investigates that assumption.

There are several reasons why these are interesting schemes to investigate. First, the local nature of the schemes allows us to carefully address the issue of identification, as the subsidised municipalities can be compared to similar, non-affected municipalities within the same national market. Second, the schemes are very focused in scope and, therefore, their effects are identifiable. Third, the data availability for Germany is particularly good, as detailed information on broadband coverage, the number of ISPs, and price data is available at the municipality level. Finally, there exist several academic papers analysing broadband markets at this level of aggregation (e.g., Falck, Gold and Heblich, 2014; Nardotto, Valletti and Verboven, 2015). These examples are useful to support methodological choices and to compare outcomes.

\footnotetext{
${ }^{9}$ According to the German Ministry of Agriculture, only $20 \%$ of the available funding was requested by the end of 2009. The remaining funds were transferred to subsequent years.

10"De minimis aid indeed refers to small amounts of state aid to undertakings (essentially companies) that EU countries do not have to notify the European Commission about. The maximum amount is $€ 200,000$ for each undertaking over a 3-year period."(https://eur-lex.europa.eu/legal-content/EN/TXT/?uri=LEGISSUM\%3A0802² pg. 1)
} 


\section{The Data}

Our empirical analysis seeks to identify the effect of the aid schemes on the broadband market and, in particular, on the availability of internet access (coverage), the entry of ISPs, and the price of broadband plans. Our identification strategy relies on a DiD framework where we compare aid-receiving municipalities with matched control municipalities based on (ex-ante) socio-demographic characteristics that should drive the incentives to invest in broadband infrastructure. These characteristics are then also used to explore possible heterogeneous effects of the aid. To perform this analysis, we combine several data sources which we describe in the remainder of this section. Before moving to the description of each dataset, we note that the empirical analysis is restricted to two states, Bavaria and Lower Saxony, due to the availability of municipality-level aid data in these two states only, as explained in the next paragraph.

Data on the state aid schemes. State aid was accessible for municipalities in the whole country, both because of the presence of the national scheme, and because most states supplemented the national scheme with regional schemes. However, we only obtained detailed municipality-specific information for two states: Bavaria and Lower Saxony ${ }^{11}$ The data for these two states have been provided by the Bavarian State Ministry for Economics, Media, Energy and Technology, and by the Lower Saxony Ministry for Economics and Transportation. Two variables are reported: i) an indicator variable for receiving the aid; and ii) the amount of the aid. This data is cross-sectional, which means that we do not know the exact moment when the funding was transferred nor when the investment was actually made by the ISP. This has implications for our empirical strategy, as we later discuss.

Data on broadband coverage and ISP entry between 2010 and 2015. We obtained data on broadband availability from TÜV Rheinland Consulting GmbH. TÜV collects geo-referenced information on internet coverage and on ISPs' network for the German Federal Ministry for Transport and Digital Infrastructure within the "Breitbandatlas" project 12 This data is aggregated at the municipality level and spans from 2010 to 2015 (and is thus very similar to the data used in Falck, Gold and Heblich 2014). It reports for each municipality/year an indicator variable for broadband availability - i.e., the percentage of the households in the municipality that could access the broadband infrastructure - at different speeds (2Mbit/s, 6Mbit/s, 16+Mbit/s) and a set of variables for the number of active ISPs per

\footnotetext{
${ }^{11}$ These were the two most important states for broadband aid, also because they implemented important additional schemes to complement the nation-wide scheme. Bavaria was the state that obtained the highest level of public support for the expansion of its broadband network. According to aggregated data obtained from the German Federal Ministry for Food and Agriculture, Bavaria alone accounted for over $40 \%$ of the money spent to support broadband infrastructure in West Germany, and Lower Saxony for about 13\%. Therefore, these two states cover more than half of the aid given under the schemes.

${ }^{12}$ See https://bit.ly/2fB2GSN.
} 
technology class - DSL, cable, mobile (LTE), fiber to the home (FTTH) ${ }^{13}$ Due to the availability of state aid data on the municipality level for only Bavaria and Lower Saxony, both located in West Germany, we requested data on all West German municipalities. We do this as a preliminary step, in order to compare the municipalities that we use in the empirical analysis to the rest of the municipalities in the country: 14

Data on the broadband market between 2005 and 2008 as well as cartography data. We complement the previous data on the broadband market with two datasets on the network infrastructure and on the geo-conformation of the terrain. The first dataset is taken from Falck, Gold and Heblich (2014) and contains information on the topology of the network, which allows for computing the number of the main distribution frames (MDFs) serving each municipality and the (linear) distance between each MDF and the municipality, an important factor driving the quality of broadband connections. Furthermore, this data reports the levels of coverage for the years 2005-2008 for the (very basic) speed of $1 \mathrm{Mbit} / \mathrm{s}$.

The second dataset was obtained from the Federal Agency for Cartography and Geodesy and is used to compute two variables, altitude and ruggedness, which capture part of the costs to deploy the infrastructure 15 Both datasets cover the entire country and, thus, also the two states on which we focus.

Data on prices of broadband plans. We obtained data on the price of all broadband plans for each prefix in Bavaria and Lower Saxony for the 2010-2015 period from ww. Teletarif.de, which is a German price-comparison website. The dataset contains a set of variables including the monthly price of the plan, a "comprehensive" monthly price which include activation costs pro-quota (assuming contract duration of 2 years), connection speed, and other features of the plan, such as the included Gigabites (when capped to a maximum per month). We focus on the broadband-only plans and we discard the plans in which broadband is bundled with other services, such as voice or TV. This choice is driven by the idea to create a clean proxy for price effects of competition at the broadband level, since disentangling the broadband component of bundles would be hard and probably subject to noise. This data is available at the level of the telephone prefix, which we mapped into municipalities, where the topology of prefix and municipality mostly coincides for small towns.

Data on socio-demographic characteristics. Data on socio-demographics characteristics have been obtained from the German Census databases collected within the Regional Statistical Data Catalog of

\footnotetext{
${ }^{13}$ The level of desegregation, both in terms of speed and technology, is important for our analysis. For example, while the aid was aimed at basic coverage (up to $2 \mathrm{Mbit} / \mathrm{s}$ ), there might have been spillover effects to higher speeds. Moreover, while the aid was supposed to be technology neutral, it was only granted to DSL and mobile technologies as both cable and fiber technologies could not meet the open access obligations that were necessary to receive the aid.

${ }^{14}$ There are good reasons to believe that the (former) East German broadband markets are still (differently) affected by the investment decisions made after the reunification, which would make them poor control groups (see Falck, Gold and Heblich 2014).

${ }^{15}$ Bundesamt fuer Kartographie und Geodiesie, see https://www.bkg.bund.de/EN/Home/
} 
the Federal Statistical Office and the statistical offices of the individual states ${ }^{16}$ For each municipality, the census reports a rich set of variables, including total population, average income, education, age structure, population density, unemployment, and the percentage of surface in each municipality used by firms. Most variables are available at the municipality level, whereas some others were only available at the more aggregate district level (each district contains on average 16 municipalities). We employ these variables in our empirical analysis as control variables as well as in the matching procedure to capture the role of demand-side factors that drive the investment decisions of ISPs.

\section{A first look at the broadband market}

In this section we describe the German broadband market between 2010 and 2015, i.e., the period of implementation of the aid schemes. We also compare the whole West German market with the two states that we focus on, Bavaria and Lower Saxony. As previously noted, the unit of observation of our analysis is the municipality, as this is the geographical unit at which both the broadband data and the state aid data are available; other data, such as prices, are re-mapped onto this level.

Table 1 reports descriptive statistics on demographic characteristics in Panel A, the broadband network in Panel B, coverage and entry of ISPs in Panel C, the state aid in Panel D, and the price of broadband plans in Panel E.

Socio-demographic characteristics and the network's structure. The socio-demographic characteristics of West Germany reported in Panel A of the table show that, on average, the size of a municipality is 7,600 inhabitants. Of those, slightly less than $30 \%$ have a college degree and approximately $55 \%$ of them are between 24 and 55 years old. The average unemployment rate is $5.6 \%$. The municipalities in Bavaria and Lower Saxony do not differ much, on average, from the other West German municipalities. They are slightly less populous and less densely populated, they are slightly richer, but not more educated as measured by the share of college graduates.

Panel B reports some information on the DSL network. The average distance between a node of the network and the municipality served by the node is 2.798 kilometers. This distance is an important factor driving the actual quality of DSL connections, as the signal strength decays with distance and this factor is taken into account by ISPs when deciding where to invest. The sample of municipalities in Bavaria and Lower Saxony displays an average distance that is very close to that of the full sample. The number of MDFs per municipality is 0.7 . This indicates that a node often serves more than one municipality in rural areas. Finally, the panel reports the terrain ruggedness index ${ }^{17}$ The average value of the index indicates that, on average, the municipalities are located in flat areas, with some variation

\footnotetext{
${ }^{16}$ See https://www.regionalstatistik.de/genesis/online

${ }^{17}$ This index is computed as in Riley, DeGloria and Elliot (1999). It is calculated as the difference in elevation values from a center cell and the eight cells immediately surrounding it. Then it averages the squares of the eight elevation difference. Finally, the index is the square root of this average. The index ranges from level $0-80$, to moderately rugged $240-497$, to extremely rugged 959 - 4367.
} 
Table 1: Descriptive Statistics

\begin{tabular}{|c|c|c|c|c|c|c|c|c|}
\hline & \multicolumn{4}{|c|}{ West German municipalities } & \multicolumn{4}{|c|}{ Bavaria and Lower Saxony } \\
\hline & Mean & Std. Dev. & Min. & Max. & Mean & Std. Dev. & Min. & Max. \\
\hline \multicolumn{9}{|l|}{ Panel A: Socio-demographics } \\
\hline Total population (1,000s people) & 7.6 & 31.8 & 0.065 & $1,429.6$ & 6.7 & 30.8 & 0.2 & $1,429.6$ \\
\hline Income (1,000s EUR) & 29.39 & 14.2 & 8 & 956.6 & 32.1 & 6.8 & 15.4 & 212.3 \\
\hline College degree $(\%)$ & 26.1 & 8.2 & 0 & 70.7 & 24 & 9.3 & 0 & 70.3 \\
\hline Population between 24 and $65(\%)$ & 54.4 & 2.7 & 31.7 & 74.7 & 54.4 & 2.3 & 36.8 & 71.6 \\
\hline Population density & 211 & 294.6 & 2.4 & 4601.2 & 173.8 & 256.6 & 3.5 & 4601.2 \\
\hline Unemployment rate $(\%)$ & 5.6 & 2 & 1.4 & 18.2 & 5.1 & 2.2 & 1.4 & 14.8 \\
\hline Area for firms and industry $(\%)$ & 0.25 & 0.56 & 1.4 & 18.2 & 0.7 & 1 & 0 & 16.4 \\
\hline \multicolumn{9}{|c|}{ Panel B: Network structure and supply-side factors } \\
\hline Distance MDF-municipality (in m) & 2,798 & 1,806 & 11.5 & 14,833 & 2,847 & 1,843 & 38 & 14,833 \\
\hline Number MDFs serving the municipality & 0.7 & 1.8 & 0 & 56 & 0.7 & 1.6 & 0 & 56 \\
\hline Ruggedness index & 38.3 & 32.7 & 0.5 & 289.1 & 29.8 & 30.2 & 0.5 & 289.1 \\
\hline \multicolumn{9}{|l|}{ Panel C: Coverage and entry of ISPs } \\
\hline DSL Coverage 1Mbit/s in 2005 & 76.3 & 20.6 & 0 & 100 & 74.3 & 19.7 & 0 & 100 \\
\hline DSL Coverage 1Mbit/s in 2008 & 92 & 11 & 0 & 100 & 90.5 & 15.4 & 0 & 100 \\
\hline DSL Coverage 2Mbit/s in 2010 & 62.3 & 36.6 & 0 & 100 & 65.1 & 32.8 & 0 & 100 \\
\hline DSL Coverage 2Mbit/s in 2015 & 86.0 & 24.5 & 0 & 100 & 90.1 & 17.7 & 0 & 100 \\
\hline DSL Coverage 6Mbit/s in 2010 & 39.9 & 37.3 & 0 & 100 & 43.8 & 35 & 0 & 100 \\
\hline DSL Coverage 6Mbit/s in 2015 & 72.5 & 33.5 & 0 & 100 & 79.6 & 25.7 & 0 & 100 \\
\hline DSL Coverage 16Mbit/s in 2010 & 17.5 & 24.5 & 0 & 100 & 18.8 & 23.8 & 0 & 100 \\
\hline DSL Coverage 16Mbit/s in 2015 & 55.2 & 36.2 & 0 & 100 & 61 & 31.5 & 0 & 100 \\
\hline Number of ISPs in 2010 & 2.8 & 1.5 & 1 & 8 & 2.8 & 1.4 & 1 & 8 \\
\hline Number of ISPs in 2015 & 5.3 & 1.3 & 2 & 11 & 5.4 & 1.2 & 3 & 11 \\
\hline \multicolumn{9}{|l|}{ Panel D: State-aid } \\
\hline Share municipalities with aid (\%) & - & - & - & - & 59.9 & - & 0 & 100 \\
\hline Funding $(€ 1,000 \mathrm{~s})$ & - & - & - & - & 86.5 & 55.9 & 10.5 & 673.7 \\
\hline \multicolumn{9}{|l|}{ Panel E: Broadband plans } \\
\hline Average effective price in 2010 & - & - & - & - & 74.3 & 0.7 & 71.5 & 75.3 \\
\hline Average effective price in 2015 & - & - & - & - & 52.6 & 0.6 & 50.3 & 54.3 \\
\hline
\end{tabular}

Total population is the resident population (in thousands) in the municipality. Income is the average income (in thousands $€)$ in the municipality. College degree is the share of population with a university degree or equivalent. Population between 24 and 65 is the share of population between 24 and 65 years old. Population density is the number of inhabitants per km². Unemployment rate is the share of people unemployed in the municipality. Area for firms and industry is the share of surface in the municipality occupied by firms and factories. Distance MDF-municipality is the linear distance in meters between the MDF and the geographical centroid of the municipality. Number MDFs serving the municipality is the number of MDFs connected to the municipality. Ruggedness index is the terrain ruggedness index, proposed in Riley, DeGloria and Elliot (1999). Variables in Panel C on coverage, DSL Coverage X Mbit/s in 2OYY is the share of households covered by broadband at minimum speed of X Mbit/s in year 20YY. Number of ISPs in 2010 and Number of ISPs in 2015 is the number of ISPs active in year 2010 and 2015, respectively. Share of municipalities with aid is the share of municipalities receiving state aid. Funding is the amount of the subsidy in thousands $€$. Average effective price in 2010 and Average effective price in 2015 are the average monthly price (including ancillary costs) for broadband connections in the municipality in 2010 and 2015 , respectively.

due to the presence of mountains, which are mainly located in the southern part of the country. In this respect, the presence in the sample of a flat state, Lower Saxony, and a more mountainous state, Bavaria, makes the sub-sample that we consider a good representation of the average municipality in 
the country. The reason for including this variable is that it proxies for some of the infrastructure costs that ISPs incur when they decide to bury cables and connect an area. These costs are greater when operating in a rugged area, thus influencing the decision to invest.

Broadband coverage and market entry. Panel $C$ of Table 1 reports information on broadband coverage at different speeds. The first two rows in the panel report the DSL coverage at the speed of at least 1Mibt/s in 2005 and 2008 respectively 18 At this (relatively low) threshold, three-quarters of the municipalities are already served in 2005 and more than $90 \%$ are served in 2008. However, this sustained growth of market coverage does not exclude laggards, as the presence of municipalities without any coverage shows (the minimum is zero). Moving to higher speed thresholds, coverage increased at all speeds during the period 2010-2015, with lower coverage rates for higher speeds. The growth of coverage can be better appreciated in the graphs reported in Figure 2. The coverage at the minimum

Figure 2: Broadband coverage at different speeds
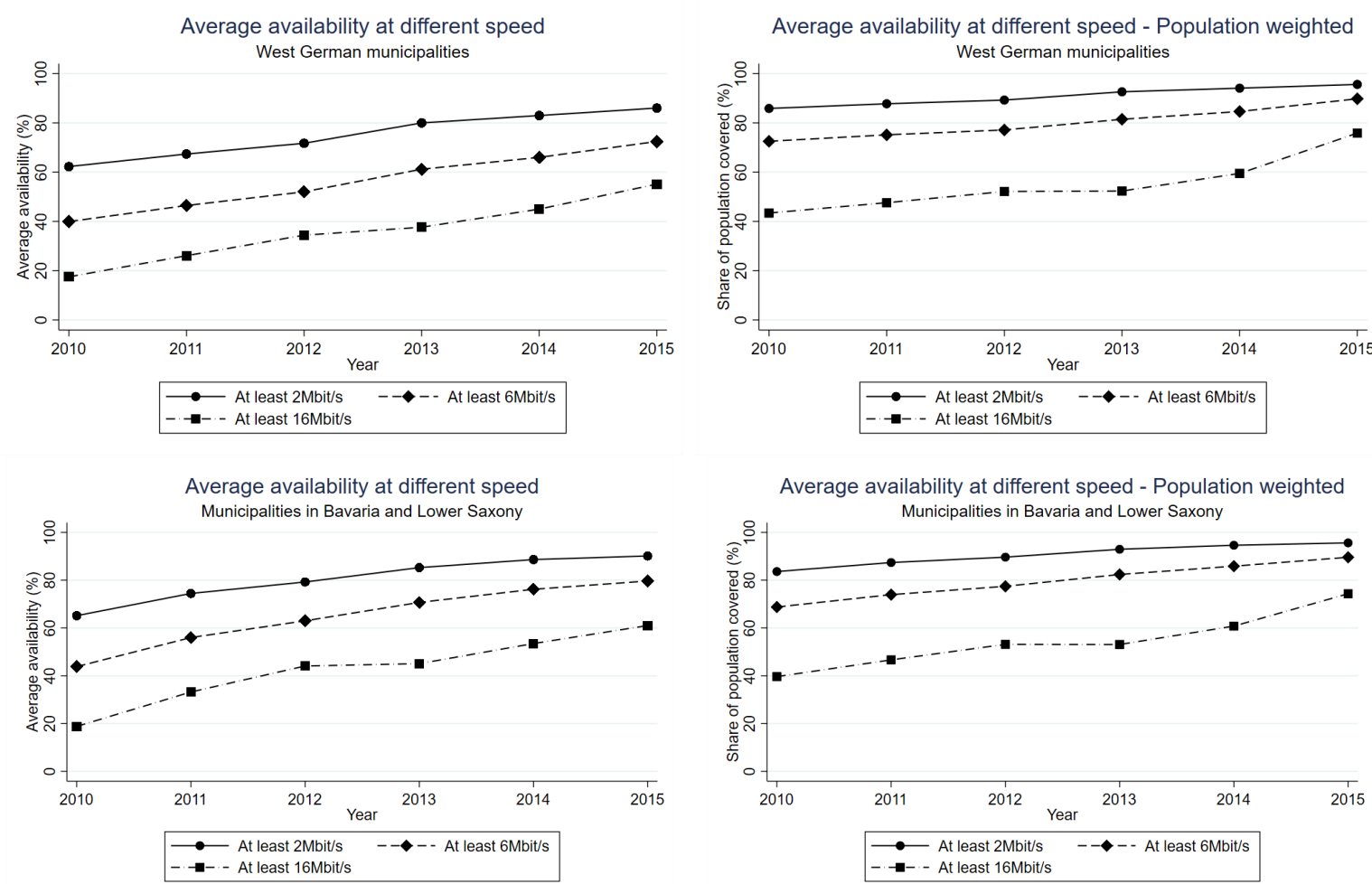

Left panel displays the average availability calculated as the share of municipalities covered at $2 \mathrm{Mbit} / \mathrm{s}$ or more, $6 \mathrm{Mbit} / \mathrm{s}$ or more, and 16Mbit/s or more; Right panel displays the share of population covered at 2Mbit/s or more, $6 \mathrm{Mbit} / \mathrm{s}$ or more, and $16 \mathrm{Mbit} / \mathrm{s}$ or more. The top panels report the two measures of coverage using all West German municipalities while the bottom panels report the two measures of coverage using only municipalities in Bavaria and Lower Saxony. Source: Our elaboration on Breitbandatlas data.

\footnotetext{
${ }^{18}$ Note that we have data on $1 \mathrm{Mibt} / \mathrm{s}$ only for the period 2005-2008. While we do not have data on higher speeds for this period.
} 
level of 2Mbit/s, which was only slightly above $60 \%$ in 2010 (top-left panel of the figure), increases by more than 20 percentage points in 5 years, a result that corresponds to almost full coverage once we look at the share of population covered. Similar to what happened for the basic speed of $2 \mathrm{Mbit} / \mathrm{s}$, coverage at the higher speeds $6 \mathrm{Mbit} / \mathrm{s}$ and $16 \mathrm{Mbit} / \mathrm{s}$ increases substantially, the latter getting close to $60 \%$, in terms of municipalities covered, and close to $80 \%$ in terms of population with access. The picture is qualitatively not different in Bavaria and Lower Saxony. These two states had very similar coverage rates with respect to the rest of the country for the 1Mbit/s speed in the period 2005 to 2008 , while they were slightly ahead in the period 2010 to 2015 compared to the rest of the country at the speeds of $2 \mathrm{Mbit} / \mathrm{s}, 6 \mathrm{Mbit} / \mathrm{s}$, and $+16 \mathrm{Mbit} / \mathrm{s}$.

This increase in market coverage went hand-in-hand with an increase in the number of ISPs active in the market. The average number of ISPs operating in a municipality almost doubles between 2010 to 2015, going from 2.8 to 5.3. In this dimension, Bavaria and Lower Saxony look very similar to the rest of the country. Table 2, providing additional information regarding the technology of the entrants reports, for 2010 and 2015, the share of municipalities with 0 to 7 active ISPs, divided by technology. From the Table one can appreciate the strong entry process in DSL and mobile broadband. Starting with DSL, more than half of the municipalities had only 1 ISP active in 2010, while five years later the median municipality had 3 ISPs. The entry process in the mobile broadband is even stronger. In 2010 , more than three-quarters of municipalities had no operator, but five years later $24 \%$ of them have 2 operators, more than $50 \%$ have 3 operators, and another $20 \%$ have 4 operators.

Finally, cable and fiber operators also grew during this time period, but to a much lesser extend than DSL and mobile operators, which is most likely related to the much higher costs to deploy the infrastructure of the former technologies 19 The result of that in terms of entry is a modest growth of the cable operators, which reduced the number of municipalities with 0 operators from almost $70 \%$ to $54.6 \%$ and to the presence in 2015 of a good number of municipalities, $25 \%$ of the total, with 2 cable operators. Fiber to the home displayed a more modest growth with the share of municipalities, with 0 operators going down from $98.7 \%$ in 2010 to $90 \%$ in 2015 mainly to host the arrival of the first operator. Only $0.7 \%$ of the municipalities had 2 or more fiber operators in 2015.20

State aid. Panel $D$ of Table 1 reports the share of municipalities receiving state aid in Bavaria and Lower Saxony. This share amounts to $59.9 \%$. Conditional on receiving funding, the average grant

\footnotetext{
${ }^{19}$ While entry in DSL requires mainly to connect white areas when these areas are still present (i.e., those targeted by the aid schemes) and to upgrade the servers in the MDFs, and entry with a mobile technology requires to install antennas or buying space in an already-existing antenna, entering a market with cable or fiber requires installing much more costly infrastructure: to create the MDF and to dig the terrain to deploy the cables (this also requires obtaining permissions, often an inherently lengthy process). Thus, the costs associated to market entry with cable or fiber are much larger than those associated to entry with DSL and mobile (although the potential speed of the connection goes in favor of the former).

${ }^{20}$ The slow take up of fiber in European countries can be simply explained by a combination of the cost factors, which limited the investments by ISPs and by the purchase decisions of internet users, who often prefer a slower but cheaper DSL connection, which still enables them to access all internet services (from e-mailing to HD movie streaming), to a more expensive fiber connection.
} 
Table 2: Frequencies of the number of ISPs in 2010 and 2015, by technology

\begin{tabular}{|c|c|c|c|c|c|c|c|c|}
\hline \multirow[b]{2}{*}{ Number of ISPs } & \multicolumn{2}{|c|}{ DSL } & \multicolumn{2}{|c|}{ Cable } & \multicolumn{2}{|c|}{ LTE } & \multicolumn{2}{|c|}{ FTTH } \\
\hline & 2010 & 2015 & 2010 & 2015 & 2010 & 2015 & 2010 & 2015 \\
\hline 0 & 4.5 & 0.2 & 68.7 & 54.6 & 77.1 & 0.2 & 98.7 & 90 \\
\hline 1 & 54.5 & 0.1 & 30.5 & 17 & 21.5 & 1.2 & 1.3 & 9.3 \\
\hline 2 & 17.8 & 35.3 & 0.8 & 25.6 & 1.4 & 24 & 0 & 0.6 \\
\hline 3 & 11.8 & 37.5 & 0 & 2.6 & 0 & 52.9 & 0 & 0.1 \\
\hline 4 & 10.3 & 18.2 & 0 & 0.2 & 0 & 20 & 0 & 0 \\
\hline 5 & 1 & 7.2 & 0 & 0 & 0 & 1.7 & 0 & 0 \\
\hline 6 & 0.1 & 1.3 & 0 & 0 & 0 & 0 & 0 & 0 \\
\hline 7 & 0 & 0.2 & 0 & 0 & 0 & 0 & 0 & 0 \\
\hline
\end{tabular}

The Table reports, for the years 2010 and 2015, the share of municipalities hosting 0 to 7 ISPs adopting the following technologies: DSL (all types), Cable, LTE, and FTTH.

amounts to $€ 86,500$. The two panels in Figure 3 show graphically the municipalities which received state aid (dark blue) and which did not receive aid (light blue) in the two states. Note that there are hints

Figure 3: : Treated municipalities in Lower Saxony (left) and Bavaria (right)
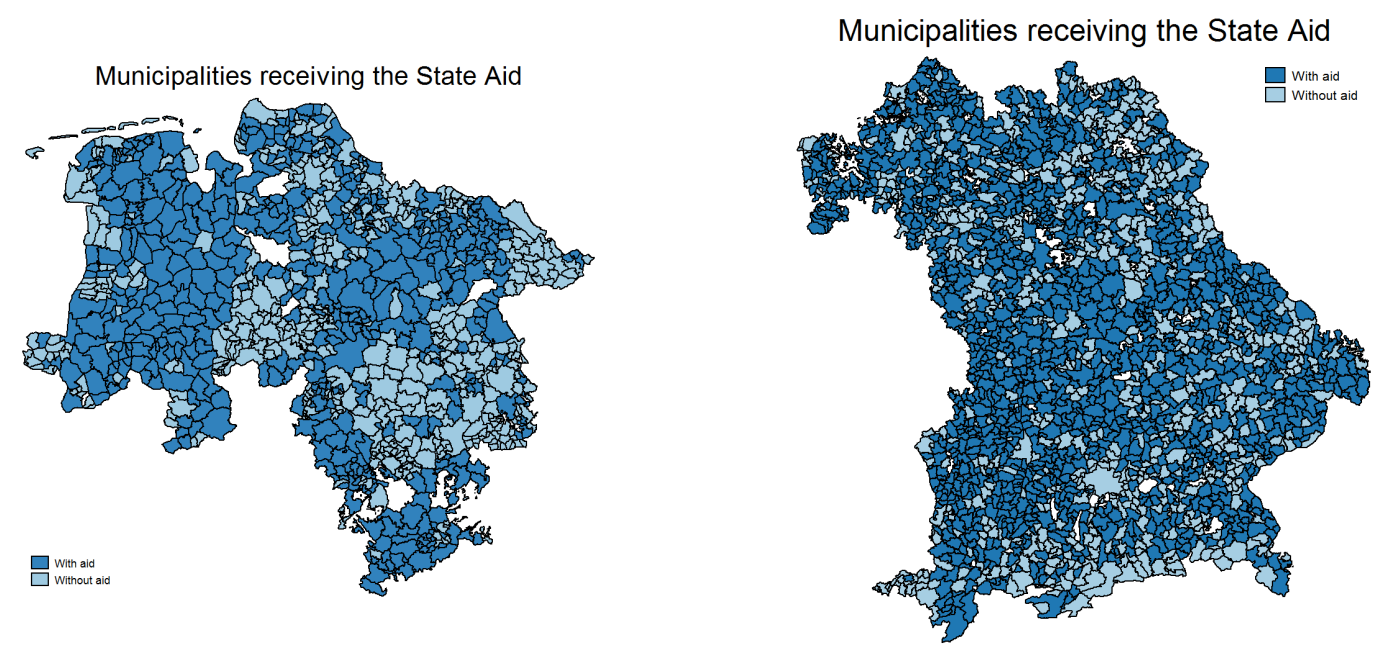

Source: Our elaboration on data from the Bavarian Stare Ministry for Economics, Media, Energy and Technology, as well as the Lower Saxony Ministry for Economics, and Transportation.

of geographic clustering in applying for the aid, especially in the state of Lower Saxony. In a robustness check, reported in subsection 6.1, we estimate a model that incorporates this aspect; we show that our main results are robust to clustering on municipalities.

Broadband plans. The last panel of Table 1. Panel E, reports the average price for broadband connections in the first and in the last year of our sample. The average price of broadband substantially decreased in the 5-years time we span with our data, going from $€ 74.3$ to $€ 52.6$. There are two factors at work that could explain this large overall fall in prices. Firstly, the sizable overall entry process in the 
market -which almost doubled the average number of competitors- could have led to lower prices ${ }^{21}$ Secondly, the decision of Deutsche Telekom (DT), the main DSL player and historical incumbent, to withdraw its T-DSL plans from the market most likely had an impact as well. DT, as historical incumbent and former monopolist, sets its plans most likely at a higher price than competitors.

\section{Empirical analysis and identification strategy}

This section seeks to quantify the effects of the state aid schemes on the broadband market. We start by discussing the identification strategy that we adopt in our empirical analysis. Then, we introduce our empirical model and we present the results of the analysis, focusing on the effect of state aid on the levels of internet coverage, on the entry of ISPs, and finally on the price of broadband connections.

\subsection{State aid, market expansion and market competition.}

Our goal is to study the effect of state aid schemes on the development of local broadband markets in rural areas. The primary expected effect of the aid scheme is to increase coverage at a higher rate compared with what the market would do without the schemes. The reasoning behind this prediction is simple. Deploying infrastructure constitutes a large cost for an ISP. This high cost needs to be compensated by the (expected) revenues from selling broadband services to end users. In rural areas, where demand is low and costs are relatively high due to low population density and relatively wide areas, ISPs often find this trade-off unfavourable. The grants, whose first goal was to eliminate remaining white areas by deploying new infrastructure, should lead to an increase in coverage in the aid-receiving areas, compared with areas that do not receive it.

The second effect of the aid we seek to study is on market entry. Market entry can be triggered by the predicted increase in market coverage, as explained above. An increase in coverage is equivalent to an increase in the market size that ISPs can serve. A larger market size could then lead into a larger number of ISPs in the market if the entry cost is not too high. With regards to entry costs, one of the main characteristics of these schemes - which helped to gain approval by the EC- was to impose open access to the newly built infrastructure. Thus, after the installation of the infrastructure, all ISPs could use it to provide broadband services in the area at a usage cost to be paid to the owner of the infrastructure. Thus, based on oligopoly theory, one can make the following prediction: with near-free entry (low fixed costs), a larger market can sustain a greater number of competitors in equilibrium 22

Finally, a larger number of competitors might also be associated with a decrease in the price for broadband connections. This prediction is more nuanced as the previous two, as it depends on the

\footnotetext{
${ }^{21} \mathrm{~A}$ negative relation between the number of competitors and market price is a standard result when the number of initial competitors is low, and has been documented in many studies; see the literature that originated by the work of Bresnahan and Reiss 1991 In the case of broadband internet, see for instance Xiao and Orazem (2011).

${ }^{22}$ See the literature originated by the seminal work by Bresnahan and Reiss (1991), and then applied in the context of the broadband market, for instance by Nardotto, Valletti and Verboven (2015)
} 
initial level of competition and on the pricing strategies of firms. If the initial level of competition is low, then one would expect that additional entry leads to a more competitive environment and, thus, to lower prices (see again Bresnahan and Reiss, 1991, and the literature based on this paper). If, on the other hand, the initial level of competition is already relatively high, then additional entry would not meaningfully alter competition and thus it might not lead to substantially lower prices. While it is difficult to measure in general the initial level of competition, we follow the entry literature and use a structural indicator as proxy for competition, i.e., the initial number of ISPs in a given municipality. In other words, our prediction is that with a lower initial number of ISPs, additional entry would lead to a larger (negative) impact on prices.

\subsection{Matching}

To identify the causal effects of the different state aid schemes on broadband availability and entry, we adopt a DiD approach where we compare municipalities in Bavaria and Lower Saxony that requested and implemented the aid to municipalities in the same states that did not. A simple DiD model would allow us to identify the average treatment effect of the aid if the treatment was random. Yet, the allocation of the aid was probably not a random process. Hence in a first step, we seek to reduce selection bias due to observable characteristics (see e.g. Aguzzoni et al. (2016) and Hosken, Olson and Smith (2015)). We do this by identifying appropriate treated and control municipalities through a matching procedure.

Specifically, we identify those municipalities that did not implement the state aid, but that had ex-ante the same attractiveness for broadband investment as those that did implement the aid. In this way, the municipalities that did not implement the aid provide the counterfactual outcome for how the subsidised municipalities would have performed without the subsidy. This would therefore mimic a situation in which the treatment, i.e., the aid, was randomly assigned.

To implement the matching procedure, we first run a regression to recover the likelihood, i.e., the "propensity score," that a municipality implemented the aid based on its observable characteristics. Second, for each treated municipality, we match a non-treated municipality which is as similar as possible, i.e., which has a propensity score as close as possible to the considered treated municipality. Note that this regression does not aim at explaining why a municipality was awarded the aid. We only look for municipalities among the non-treated that are as similar as possible to the treated with regards to observed characteristics.

The matching is performed based on 2008 variables (or the closest in time to that year) in order to avoid any spurious correlation with the effect of the treatment. By choosing a time period well before the treatment, we are more certain to include only variables that are unaffected ${ }^{23}$ Furthermore, following the matching literature we use one measure of the outcome pre-treatment (e.g. Heckman,

${ }^{23}$ Our empirical strategy builds on the so-called conditional independence assumption (e.g. Heckman, Ichimura and Todd 1998). This assumption requires that the outcome variable is independent from the treatment, conditional on the propensity score. Therefore, when we implement the matching procedure we choose a set of explanatory variables satisfying this 
Ichimura and Todd, 1997). Specifically, we use DSL availability from Falck, Gold and Heblich (2014) which covers internet availability at the municipality level for the years 2005-2008. This variable is also used again below in the context of the "common trend" assumption needed for a clean DiD analysis.

When doing matching, the trade-off lies between a model that is rich enough to capture the main drivers of investment and entry, but that also ensures to achieve balancing between treated and control areas. We converged to a specification entailing what we consider being the core set of characteristics. These include demand-based variables (population, income, education, percentage area for firms and industry) and supply-based variables (distance to the MDF, ruggedness) ${ }^{24}$

The model we estimate through a logit regression as a first step of the matching procedure is:

$$
\operatorname{Aid}_{m}=\alpha+\eta X_{m}+u_{m}
$$

where $A i d_{m}$ is an indicator for the municipality having received state aid and $X_{m}$ is a vector of demand and supply characteristics: population and population squared, population density, income, unemployment, the share of inhabitants with a college degree, the share of population between 16 and 64 years old (and thus at working age), the ruggedness index (computed as described in footnote 17), the distance between the centroid of the municipality and the MDF, the share of land in the municipality devoted to firms and industry, and the coverage of 1Mbit/s in 2008.

Table 3 reports the estimates for equation (1), whereas Figure 4 shows the frequency distributions of the propensity scores for the treated and untreated municipalities. As the Figure shows, the frequency distributions of the propensity scores of the two groups of municipalities are similar, indicating that there is a good set of municipalities without aid that can be matched with those receiving aid.

Based on this information we perform a nearest-neighbor matching without replacement. When there is enough overlap between units in the treated group and a subset of the control group, then matching without replacement is the better choice (see Dehejia and Wahba, 2002). The matching algorithm pairs 2,086 out of 3,009 treated municipalities.

The quality of the match is represented in Tables 4 For each variable, it shows how matching improves the balance between treated and control. For example, in the case of population density, the pre-match difference amounts to more than $22 \%$, and the difference between treated and untreated is significantly different. After the matching, the bias is only just above $2 \%$ which amounts to a reduction in bias of more than $90 \%$. Moreover, the difference post-match between the treated and untreated is now not significant anymore. Overall, the covariate imbalance before matching amounts to $13.5 \%$ and after matching to only $3.2 \%$, which indicates a clear improvement due to matching on observables 25

condition. Specifically, we only include variables that are expected to simultaneously influence both the treatment and the outcome.

${ }^{24}$ Note that including more variables in the matching procedure did not affect the qualitative results. It only reduced the number of matches and, hence, the number of observations in the main regression.

${ }^{25}$ This is further confirmed by the fact that the pseudo- $R^{2}$ of a probit regression of the propensity score on all variables is almost 20 times larger (0.04) for the unmatched sample than for the matched one (0.002). Moreover, the likelihood-ratio test 
Table 3: Propensity score regression

\begin{tabular}{|c|c|c|c|c|}
\hline \multicolumn{5}{|c|}{ Dependent variable: state aid } \\
\hline & Coeff. & Std. err. & $d y / d x$ & Std. err. \\
\hline Population & $0.356 * * *$ & $(0.059)$ & $0.08 * * *$ & $(0.013)$ \\
\hline Population $^{2}$ & $-0.006 * * *$ & $(0.001)$ & $-1 \mathrm{e}-3 * * *$ & $(0.3 e-3)$ \\
\hline Population density & $-0.002 * * *$ & $(0.000)$ & $-4 \mathrm{e}-4 * * *$ & $(0.6 \mathrm{e}-4)$ \\
\hline Income & 0.003 & $(0.008)$ & $7 e-4$ & $(0.001)$ \\
\hline College degree & $-0.017 * * *$ & $(0.006)$ & $-4 \mathrm{e}-3 * * *$ & $(0.001)$ \\
\hline Work age & 0.011 & $(0.017)$ & $2.5 \mathrm{e}-3$ & $(0.004)$ \\
\hline Unemployment & $-0.102 * * *$ & $(0.024)$ & $-0.02 * * *$ & $(0.005)$ \\
\hline Distance to MDF & $0.198 * * *$ & $(0.024)$ & $0.04 * * *$ & $(0.005)$ \\
\hline Ruggedness & -0.002 & $(0.001)$ & $-0.4 e-3$ & $(0.3 e-3)$ \\
\hline Area firms and industry & 0.081 & $(0.056)$ & 0.018 & $(0.013)$ \\
\hline DSL 2008 & 0.535 & $(0.362)$ & 0.12 & $(.0812)$ \\
\hline Constant & -0.271 & $(1.046)$ & & \\
\hline Observations & 3009 & & & \\
\hline Log-likelihood & -1927.168 & & & \\
\hline Pseudo $\mathrm{R}^{2}$ & 0.049 & & & \\
\hline
\end{tabular}

The dependent variable Aid is an indicator which takes value 1 if the municipality receives state aid. Population is the number of inhabitants in the municipalities (in thousands) and Population ${ }^{2}$ is its squared value. Population density is the number of inhabitants per $\mathrm{km}^{2}$. Income is the average income in the municipality (in thousands euro). Work age is the share of population between 16 and 64 years old. Unemployment is the unemployment rate in the municipality. Distance to the MDF is the linear distance in $\mathrm{km}$ between the centroid of the municipality and the MDF. Ruggedness is the ruggedness index computed as described in footnote 17 Area firms and industry is the share of land in the municipality devoted to firms and industry. DSL 2008 is the coverage of 1Mbit/s in 2008 in the municipality. Robust standard errors in parentheses. *,**, and $* * *$ denote significance at the 10,5 , and 1 percent level, respectively. Marginal effects are computed with the delta-method.

Finally, we provide a last test for our identification strategy by examining trends in the outcome variable before the start of our treatment. Due to data limitations, we cannot asses the common trend assumption for all our outcome variables, but we can show it for the broadband coverage at the speed of $1 \mathrm{Mibt} / \mathrm{s}{ }^{26}$ The graph is reported in Figure 5 and clearly indicates that for this speed, the levels of coverage in the two groups of municipalities evolve in such a way that the common trend hypothesis is satisfied. Therefore, we are confident that our matching produced a reasonable counterfactual to perform a clean DiD analysis.

cannot reject the joint significance of all regressors when using the unmatched sample but it can reject this hypothesis when using the matched sample.

${ }^{26}$ As discussed in Section 3 , our main dataset covers the years 2010 to 2015 , with the bulk of state aid schemes being implemented between 2011 and 2013. The second data on the broadband market used in Falck, Gold and Heblich (2014) covers the period 2005 to 2008 and thus it is suiTable for a common trend analysis pre-treatment. However, in this data, the only variable on broadband diffusion is coverage at $1 \mathrm{Mbit} / \mathrm{s}$, while information on coverage at higher speeds or on the number of ISPs is not available. 
Figure 4: Propensity score distributions.

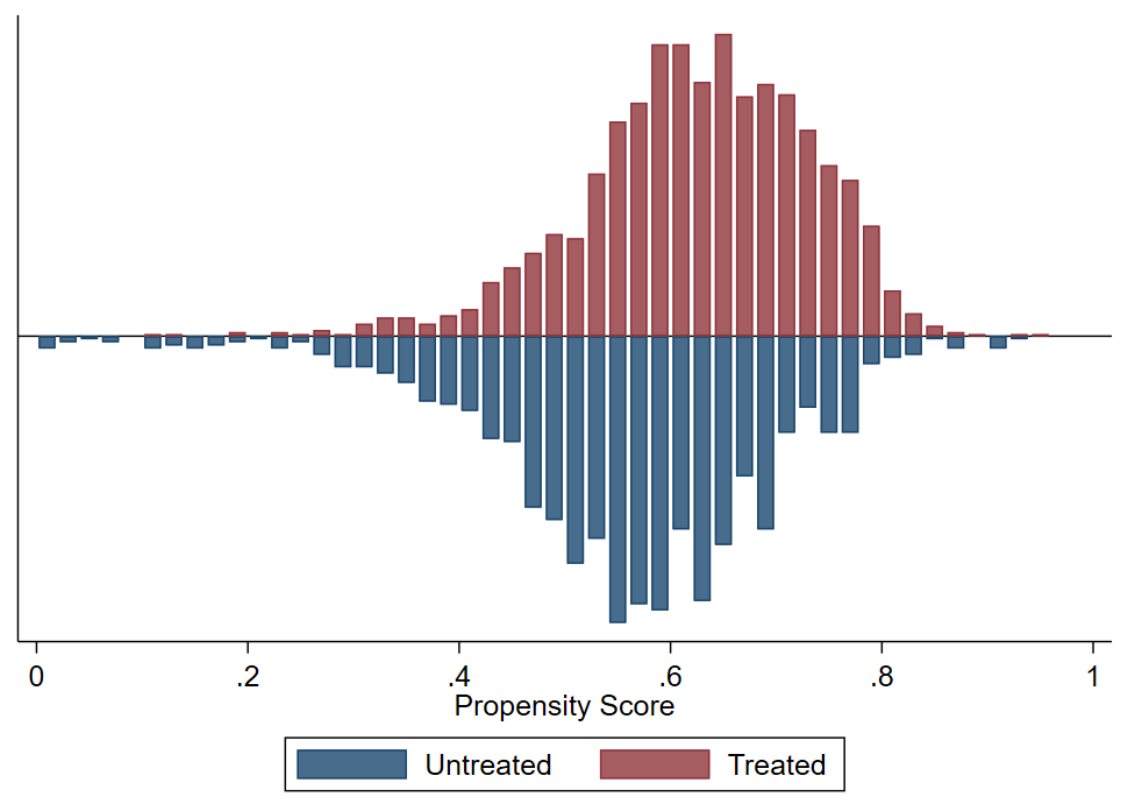

Empirical distributions of the propensity score estimated in model (1) for municipalities which received versus not receive the state aid.

Figure 5: Trends 1Mbit/s coverage

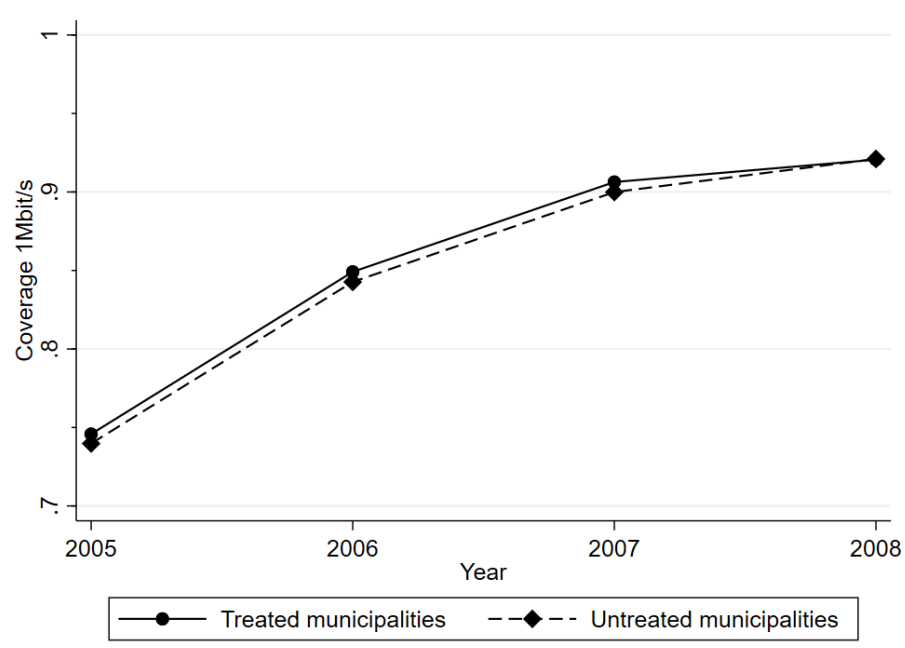

\subsection{Average Treatment Effect}

The propensity score matching procedure described in the previous section matches each municipality receiving state aid with a municipality that did not receive any funding, based on the score. Thus, we 
Table 4: Balancing

\begin{tabular}{lr|rrrr|rr}
\hline \hline & & \multicolumn{2}{|c}{ Mean } & \multicolumn{2}{c|}{ (\%) reduction } & \multicolumn{2}{c}{ t-test } \\
Variable & Sample & Treated & Control & (\%) bias & $\|$ bias $\|$ & $\mathrm{t}$ & $p>|t|$ \\
\hline Population & Unmatched & 6.07 & 7.73 & -5.0 & & -1.46 & 0.145 \\
& Matched & 6.42 & 5.81 & 1.8 & 62.9 & 0.82 & 0.410 \\
Pop. dens. & Unmatched & 149.43 & 210.95 & -22.6 & & -6.49 & 0.000 \\
& Matched & 166.5 & 160.67 & 2.1 & 90.5 & 0.67 & 0.505 \\
Income & Unmatched & 32.258 & 32.483 & -3.5 & & -0.97 & 0.333 \\
& Matched & 32.163 & 32.19 & -0.4 & 87.8 & -0.10 & 0.919 \\
College & Unmatched & 22.148 & 23.886 & -22.0 & & -5.98 & 0.000 \\
& Matched & 23.576 & 23.086 & 6.2 & 71.8 & 1.43 & 0.151 \\
Work age & Unmatched & 54.313 & 54.043 & 11.5 & & 3.11 & 0.002 \\
& Matched & 54.08 & 54.143 & -2.7 & 76.8 & -0.62 & 0.536 \\
Unemployment & Unmatched & 5.256 & 5.673 & -20.4 & & -5.52 & 0.000 \\
& Matched & 5.712 & 5.525 & 9.1 & 55.3 & 2.03 & 0.043 \\
Distance MDF & Unmatched & 3.095 & 2.475 & 34.1 & & 9.18 & 0.000 \\
& Matched & 2.557 & 2.624 & -3.7 & 89.2 & -0.88 & 0.377 \\
Ruggedness & Unmatched & 29.87 & 29.79 & 0.2 & & 0.07 & 0.946 \\
& Matched & 29.96 & 30.42 & -1.5 & -504.5 & -0.33 & 0.739 \\
Area firms & Unmatched & 0.599 & 0.702 & -10.3 & & -2.84 & 0.005 \\
& Matched & 0.641 & 0.602 & 4.0 & 61.5 & 1.03 & 0.301 \\
DSL 2008 & Unmatched & 0.918 & 0.923 & -5.3 & & -1.43 & 0.152 \\
& Matched & 0.921 & 0.921 & -0.4 & 92.0 & -0.09 & 0.925 \\
\hline \hline
\end{tabular}

Population is the number of inhabitants in the municipalities (in thousands) and Population ${ }^{2}$ is its squared value. Population density is the number of inhabitants per $\mathrm{km}^{2}$. Income is the average income in the municipality (in thousands euro). Work age is the share of population between 16 and 64 years old. Unemployment is the unemployment rate in the municipality. Distance to the $M D F$ is the linear distance in $\mathrm{km}$ between the centroid of the municipality and the MDF. Ruggedness is the ruggedness index computed as described in footnote 17 Area firms and industry is the share of land in the municipality devoted to firms and industry. DSL 2008 is the coverage of 1Mbit/s in 2008 in the municipality.

retain in the sample only the matched pairs which we use for the analysis of the effects of state aid on the broadband market.

The empirical model that we employ to estimate the effect of the aid is reported in equation (2), where $p$ indicates two paired municipalities (by the matching procedure), and $t$ is time.

$$
\Delta y_{p t}=\alpha+\gamma \text { Post }_{t}+\lambda \Delta X_{p t}+\mu_{p}+\varepsilon_{p t} .
$$

Thus, $\Delta y_{p t}$ is the difference in the outcome of interest between a treated municipality and the paired, non-treated, control municipality at year $t$. The outcomes we focus on are the broadband coverage at different speeds, the number of ISPs offering internet services, and the price of internet connections. As control variables $X_{p t}$, we employ the time-varying differences in market demand and supply conditions captured by the changes in socio-demographic variables. All factors that are not time-varying are captured by the municipality-pair fixed-effects $\mu_{p}$. The explanatory variable of interest is the indicator variable Post $_{t}$ which is equal to one for the post-intervention year 2015, whereas the year of comparison 
(the base year) is the year 2010 ${ }^{27}$ Therefore, the estimated coefficient $\gamma$ measures the average treatment effect of the state aid, as it captures the difference over time of the difference in outcomes across treated and matched non-treated municipalities. This coefficient quantifies the additional variation experienced by the outcome of those municipalities, which were affected by the scheme, with respect to the average outcome change for those municipalities, which were not implementing the aid. The error term $\varepsilon_{p t}$ is assumed to be heteroskedastic and correlated among municipality-pairs; results are robust to clustering errors at the Kreis (the next administrative unit) or state-level.

\subsubsection{Effectiveness of the Aid - Broadband Availability}

Table 5 reports the effect of the aid on broadband availability. We compare the evolution of broadband availability for municipalities that received aid to the corresponding matched municipality that did not receive any subsidy. The former experienced a large and significant increase in availability if compared to the latter. This effect ranges between an additional increase of more than $14 \%$ for availability of connections at $2 \mathrm{Mbits} / \mathrm{s}$ to a $21 \%$ increase for availability of connections at $6 \mathrm{Mbits} / \mathrm{s}$ speed, as well as speed larger than $16 \mathrm{Mbit} / \mathrm{s}$.

Table 5: Regressions for broadband coverage.

\begin{tabular}{|c|c|c|c|}
\hline \multicolumn{4}{|c|}{ Dependent variable: $\Delta$ Coverage at different speeds } \\
\hline & $\begin{array}{c}2 \mathrm{MB} / \mathrm{s} \\
(1)\end{array}$ & $\begin{array}{c}6 \mathrm{MB} / \mathrm{s} \\
(2)\end{array}$ & $\begin{array}{c}16 \mathrm{MB} / \mathrm{s} \\
(3)\end{array}$ \\
\hline Post & $\begin{array}{c}14.40 * * * \\
(1.00)\end{array}$ & $\begin{array}{c}21.14 * * * \\
(1.25)\end{array}$ & $\begin{array}{c}20.56 * * * \\
(1.29)\end{array}$ \\
\hline$\Delta X$ & YES & YES & YES \\
\hline$\mu$ & YES & YES & YES \\
\hline Average coverage in 2010 & 65.1 & 43.8 & 18.8 \\
\hline Average change between 2010 and 2015 & 25 & 35.8 & 42.2 \\
\hline $\mathrm{R}^{2}$ & 0.167 & 0.216 & 0.196 \\
\hline Observations & 2086 & 2086 & 2086 \\
\hline
\end{tabular}

The dependent variables are the changes between 2015 and 2010 of the differences between paired municipalities in the share of population that can access the internet at a speed of at least 2Mbit/s, 6Mib/t and 16Mibt/s. Post is an indicator that takes value 1 in 2015 (posttreatment) and 0 in 2010 (pre-treatment). The vector of controls $\Delta X$ includes the changes in Population and Population ${ }^{2}$, Population density, Income, Work age, Unemployment, and Area firms and industry. $\mu$ is the municipality-pair fixed effect. The standard errors in parentheses are clustered at the level of the paired municipalities. *, **, and *** denote significance at the 10,5 , and 1 percent level, respectively.

Comparing the estimated effect of the state aid with the average increase in coverage experienced during the period between 2010 and 2015, we obtain the following percent changes due to the aid: a $57.6 \%$ increase for the $2 \mathrm{Mbit} / \mathrm{s}$, a $59.1 \%$ increase for the $6 \mathrm{Mbit} / \mathrm{s}$, and a $48.7 \%$ increase for the

\footnotetext{
${ }^{27}$ In almost all specifications, we only use two years of data. In one of the extensions, instead, we make use of the full panel of 5 years.
} 
$16 \mathrm{Mbit} / \mathrm{s}$. Therefore, our analysis supports the view that the aid was indeed effective in increasing availability by a substantial amount.

Based on the estimates in Table 5, we can make a back-of-the-envelope calculation for the cost per potentially connected household in a given municipality $i$. For this calculation we use the simple formula in (3):

$$
\text { Cost }_{i}=\frac{\text { TotAid }_{i}}{\hat{\gamma} \times \text { Population }_{i}},
$$

where Tot Aid is the amount of state aid spent in the municipality and Population is the number of inhabitants. For example, given $\hat{\gamma}=14.4 \%$ for $2 \mathrm{Mbit} / \mathrm{s}$, on average, the aid potentially covered an extra 729 households per municipality. Therefore, on average, each extra covered household cost ca. $€ 235$, given an average aid amount of $€ 86,500$ (see Table 1). The numbers are more favourable -i.e., less costly per household- for higher speeds.

\subsubsection{Impact on Competition - Entry}

The previous section showed that the state aid increased broadband coverage by a substantial amount. Then, as we hypothesized in section 5.1, this extra-increase in market size coupled with an open access obligation, should attract more ISPs into the local market compared with a market that has not experienced this same increase in coverage. Assessing this hypothesis is the main goal of this subsection.

Besides the effect on the overall number of ISPs, our data also gives us the possibility to study whether the effect of the aid has been heterogeneous with respect to the technology adopted. Related to this aspect, it is important to observe that the aid was aimed to be technologically neutral. Yet, only DSL and mobile (LTE) were effectively within the scope of the schemes - either as direct beneficiaries of the aid, or through given access to the subsidised infrastructure - since one necessary condition for receiving the aid was the open access obligation. Since cable and fiber technologies could at that time not comply with these obligations because of their technical specifications, they were effectively excluded from obtaining the aid. Moreover, while both cable and fiber deployment could in principle be done using access to ducts built for the basic infrastructure, it is very unlikely that this was the case ${ }^{28}$

We estimate model (2) where now the dependent variable is the number of ISPs operating in a municipality. First, we look at the total number of ISPs, and then we focus on the 4 technologies: DSL, Cable, Mobile (LTE), and Fiber (FTTH). Table 6 reports the results of the estimations. The coefficient estimates for the Post indicator variable identify again the average treatment effect. The estimated coefficient in the first column indicates an increase in the number of ISPs in the municipalities that received the aid that amounts to 0.21 more entrants. This effect is statistically significant and, compared with a general average increase of 2.6 ISPs over the 5 years, amounts to an additional increase of $8 \%$. As expected, this effect is the strongest for the DSL market, which was mostly subsidized. On average,

\footnotetext{
${ }^{28}$ Indeed, both fiber and cable technologies are generally deployed using new infrastructure including distribution cabinets and ducts.
} 
treated markets observe 0.16 more DSL entrants over the period 2010-2015 compared to the control group: an additional increase of $10 \%$. For mobile markets, the other technology that was partially supported, the effect is instead not significant.

Table 6: Regressions for the number of ISPs.

\begin{tabular}{|c|c|c|c|c|c|}
\hline \multicolumn{6}{|l|}{ Dependent variable: $\Delta$ Number of ISPs } \\
\hline & $\begin{array}{l}\text { All } \\
(1)\end{array}$ & $\begin{array}{l}\text { DSL } \\
\text { (2) }\end{array}$ & $\begin{array}{c}\text { Cable } \\
\text { (3) }\end{array}$ & $\begin{array}{l}\text { LTE } \\
(4)\end{array}$ & $\begin{array}{l}\text { FTTH } \\
(5)\end{array}$ \\
\hline Post & $\begin{array}{c}0.21 * * * \\
(0.05)\end{array}$ & $\begin{array}{c}0.16^{* * * *} \\
(0.04)\end{array}$ & $\begin{array}{c}0.06^{* * * *} \\
(0.02)\end{array}$ & $\begin{array}{l}-0.02 \\
(0.04)\end{array}$ & $\begin{array}{c}0.05 * * * \\
(0.01)\end{array}$ \\
\hline$\Delta X$ & YES & YES & YES & YES & YES \\
\hline$\mu$ & YES & YES & YES & YES & YES \\
\hline Average number of ISPs in 2010 & 2.8 & 1.74 & 0.29 & 0.3 & 0.008 \\
\hline Average change between 2010 and 2015 & 2.6 & 1.6 & 0.21 & 2.88 & 0.077 \\
\hline $\mathrm{R}^{2}$ & 0.017 & 0.016 & 0.011 & 0.000 & 0.013 \\
\hline Observations & 2086 & 2086 & 2086 & 2086 & 2086 \\
\hline
\end{tabular}

The dependent variables are the changes between 2015 and 2010 of the differences between paired municipalities in the number of ISPs. Post is an indicator that takes value 1 in 2015 (post-treatment) and 0 in 2010 (pre-treatment). The vector of controls $\Delta X$ includes the changes in Population and Population ${ }^{2}$, Population density, Income, Work age, Unemployment, and Area firms and industry. $\mu$ is the municipality-pair fixed effect. The standard errors in parentheses are clustered at the level of the paired municipalities. *, **, and *** denote significance at the 10,5 , and 1 percent level, respectively.

We also observe that the aid had a significant positive effect on technologies that were not supported by the state aid schemes. We find a statistically significant effect of 0.06 more cable operators as well as 0.05 more entrants in the FTTH technology. Given the small growth experienced by those markets in 5 years, the estimated effects are sizable percentage-wise, given the overall small growth in these technologies: an additional $28.6 \%$ for cable operators, and $64.9 \%$ for the fiber to the home. While this is an interesting finding -there seem to exist spillovers from subsidised technologies to other technologies- we have unfortunately no information on what exact mechanisms are at play. One possible explanation, as highlighted in section 5.1, is that this entry process was driven by demandrelated factors: the aid has led to higher coverage and therefore a higher potential demand, which, in turn, made the investment by these alternative technologies more attractive.

Overall, the scheme led to more entry in the aid-receiving municipalities. From the point of view of state aid control, the results are unequivocal: the aid has led to relatively more ISPs serving those municipalities that received subsidies. In other words, these municipalities have enjoyed more entry. Thus, the competition requirement of state aid control has been satisfied: the aid has not distorted product market competition in the sense that it has not harmed rivals.

\subsubsection{Impact on Competition - Prices}

In this section, we add to the classic measure of competition in state aid (rivals) by exploring another important dimension of competition which directly affects consumer welfare, and as such is more in 
line with other areas of competition policy: prices. We are interested in studying how the local prices for broadband plans respond to the application of state aid which, as we have shown so far, increased the number of ISPs offering broadband internet connection. An increase in the number of competitors is generally associated with a number of positive consequences for consumers, such as lower prices. Of course, this reasoning only holds whenever an increase in the number of competitors leads to an increase in the level of competition. Therefore, after investigating the average effect of the aid on prices, we look at the potentially heterogenous effect as a function of the level of initial competition, which is proxied by the initial number of competitors.

To this goal, as a first step we estimate model (2) where we compare the average (posted) price for a broadband plan in municipalities that received state aid against the price in the municipalities that did not receive state aid. Estimation results are reported in column (1) of Table 7. The estimates show a reduction of the price of broadband plans due to the implementation of state aid. This reduction however, is small in size -7 cents of a euro- but it is statistically significant at the $5 \%$ level. Compared with the average price decrease for a broadband connection during the 5 years that we cover in the data, this amounts to $0.3 \%$ of the change in prices.

Table 7: Price regression

\begin{tabular}{|c|c|c|c|}
\hline \multicolumn{4}{|l|}{ Dependent variable: $\Delta$ Average price } \\
\hline & Panel FE & Panel FE & Panel IV \\
\hline Post & $\begin{array}{c}-0.072 * * \\
(0.034)\end{array}$ & & \\
\hline$\Delta$ Number of ISPs & & $\begin{array}{c}-0.120 * * * \\
(0.021)\end{array}$ & $\begin{array}{c}-0.336^{* * *} \\
(0.164)\end{array}$ \\
\hline$\Delta X$ & YES & YES & YES \\
\hline$\mu$ & YES & YES & YES \\
\hline Average effective price in 2010 & 74.3 & & \\
\hline Average change between 2010 and 2015 & -21.7 & & \\
\hline $\mathrm{R}^{2}$ & 0.004 & 0.033 & -0.075 \\
\hline F-test & & & 17.491 \\
\hline Observations & 2086 & 2086 & 2086 \\
\hline
\end{tabular}

The dependent variables is the change between 2015 and 2010 of the differences between paired municipalities in the average price of broadband plans. Post is an indicator hat takes value 1 in 2015 (post-treatment) and 0 in 2010 (pre-treatment). $\Delta$ Number of ISPs is the change between 2015 and 2010 of the differences between paired municipalities in the number of ISPs. The vector of controls $\Delta X$ includes the changes in Population and Population ${ }^{2}$, Population density, Income, Work age, Unemployment, and Area firms and industry. $\mu$ is the municipality-pair fixed effect. The standard errors in parentheses are clustered at the level of the paired municipalities. *,**, and *** denote significance at the 10,5 , and 1 percent level, respectively.

Such a small effect of the aid on prices could be explained by several factors. Firstly, the data provides information on (posted) prices, but there is no quantity information. Thus, we cannot reweigh the plans based on market shares and thus obtain a price measure that is closer to the actual price 
faced by consumers. Secondly, ISPs compete at the local level for final users, but price their product nationally, thus offering the same menu in all municipalities they serve. Furthermore, these are quite heterogeneous menus that cover all speeds from the lowest to the highest that can be supported by the technology installed in the local area.

Overall, our evidence shows a moderate effect of state aid in reducing the prices for final users. However, we hinted at the link between market structure (number of competitors) and price as a channel through which the state aid could generate an effect in local markets. Hereafter, we explore that channel in more detail. As a first step, we propose an alternative empirical model, reported in (4), where the time change in the difference in average price between a treated municipality and the paired, non-treated, control municipality is a function of the difference in average number of firms.

$$
\Delta p_{p t}=\alpha+\delta \Delta n \text { firms }_{p t}+\lambda \Delta X_{p t}+\mu_{p}+\varepsilon_{p t}
$$

Thus, instead of relating the change in prices directly to the aid (in the previous model captured by the Post indicator), we now link this to the change in the number of competitors between paired municipalities. The estimates of this model are reported in column (2) of Table 7 As expected, the estimated coefficient is negative, indicating that a higher number of ISPs negatively affects the price. The estimated effect of an additional competitor in the local market amounts to a 12 cent reduction in average prices. The effect is still small, but the estimated coefficient has a higher statistical significance.

Notice that, on average, treated municipalities experienced 0.21 additional entrants if compared to the control group as shown in Table 6. Therefore, the implied effect of this average change in the number of competitors due to the aid is 12 euro cents $\times 0.21$, which amounts to ca 2.5 euro cents. This effect is smaller than the effect of the aid on prices measured in the first column. This fact is most likely driven by the potential endogeneity of the market structure, which would imply a downward bias in the coefficient estimate. Thus, given the results on the effect of the aid on entry reported in section 5.3.2, it is natural to exploit the arrival of the state aid as an instrument for the market structure. Therefore, in column (3) of Table 7 we report the 2SLS estimates of model (4) where we instrument $\Delta n$ firms with the Post indicator ${ }^{29}$ When we instrument for the number of firms, the impact of the number of ISPs on prices becomes about three times larger. Thus, the impact of the additional entry induced by the aid is now around 7.15 euro cents ( 34 euro cents $\times 0.21$ ) which corresponds to the reduced-form effect of the aid on prices reported in column 1.

In a final step, we further exploit how state aid impacted prices, but this time we allow for a nonlinear effect, depending on the original market structure. Thus, we estimate model (2), as we did in the first column of Table 7, but this time we split the sample based on the market structure in the baseline year 2010. Results are reported in columns (1) to (5) of Table 8 In the first column we report the estimates based on the sample of municipalities with 0 or 1 ISPs in 2010 (i.e., up to monopoly pre-

\footnotetext{
${ }^{29}$ Not surprisingly given our previous results, the first stage regression works well, as aid is a good instrument for the change in the number of firms.
} 
aid), in the second column the estimates based on the municipalities with 2 or fewer ISPs in 2010 (up to duopoly), and so on until column (5) which reports the estimates of the model where we use the municipalities with 5 or fewer ISPs in 2010. The findings are in line with the intuition that the price effects of the aid are more pronounced when initial competition is lower: the negative impact of entry on prices is larger whenever the initial market structure is more concentrated. Indeed, the impact is most negative -a reduction of ca. 25 euro cents- when the initial number of ISPs in the market is zero or one, while the impact is lowest - a reduction of ca. 8 euro cents- when there are already 5 ISPs present. This finding is confirmed in the last estimation (column (6)), where we interact the variable that captures the change in the number of ISPs with the Post indicator. In line with the previous results, the effect or increasing the number of ISPs is negative, but each additional initial ISP in 2010 -i.e., in the original market structure- has a moderating effect on the total downward impact on prices.

Table 8: Price regression: Interaction with market structure

\begin{tabular}{|c|c|c|c|c|c|c|}
\hline \multirow[t]{2}{*}{ Dependent variable: $\Delta$ Average price } & \multicolumn{5}{|c|}{ Number of firms in 2010} & \multirow[b]{2}{*}{$\begin{array}{l}\text { All } \\
(6)\end{array}$} \\
\hline & $\begin{array}{c}\text { Up to } \\
\text { monopoly } \\
(1)\end{array}$ & $\begin{array}{c}\text { Up to } \\
\text { duopoly } \\
\text { (2) }\end{array}$ & $\begin{array}{c}\text { Up to } \\
\text { triopoly } \\
(3)\end{array}$ & $\begin{array}{c}\text { Up to } \\
4 \text { firms } \\
(4)\end{array}$ & $\begin{array}{c}\text { Up to } \\
5 \text { firms } \\
(5)\end{array}$ & \\
\hline Post & $\begin{array}{c}-0.248 * * * \\
(0.059)\end{array}$ & $\begin{array}{c}-0.209 * * * \\
(0.043)\end{array}$ & $\begin{array}{c}-0.234 * * * \\
(0.036)\end{array}$ & $\begin{array}{c}-0.189 * * * \\
(0.033)\end{array}$ & $\begin{array}{c}-0.084 * * \\
(0.034)\end{array}$ & $\begin{array}{c}-0.686 * * * \\
(0.153)\end{array}$ \\
\hline Post $\times$ Num. of ISPs $_{2010}$ & & & & & & $\begin{array}{c}0.111 * * * \\
(0.028)\end{array}$ \\
\hline$\Delta X$ & YES & YES & YES & YES & YES & YES \\
\hline$\mu$ & YES & YES & YES & YES & YES & YES \\
\hline Average effective price in 2010 & 74.3 & 74.3 & 74.3 & 74.3 & 74.3 & 74.3 \\
\hline Average change between 2010 and 2015 & -21.7 & -21.7 & -21.7 & -21.7 & -21.7 & -21.7 \\
\hline $\mathrm{R}^{2}$ & 0.088 & 0.047 & 0.056 & 0.034 & 0.006 & 0.019 \\
\hline Observations & 372 & 966 & 1434 & 1804 & 2040 & 2086 \\
\hline
\end{tabular}

The dependent variables is the change between 2015 and 2010 of the differences between paired municipalities in the average price of broadband plans. Post is an indicator that takes value 1 in 2015 (post-treatment) and 0 in 2010 (pre-treatment). $\Delta$ Number of ISPs is the change between 2015 and 2010 of the differences between paired municipalities in the number of ISPs. The vector of controls $\Delta X$ includes the changes in Population and Population ${ }^{2}$, Population density, Income, Work age, Unemployment, and Area firms and industry. $\mu$ is the municipality-pair fixed effect. The standard errors in parentheses are clustered at the level of the paired municipalities. *, **, and *** denote significance at the 10,5 , and 1 percent level, respectively.

In sum, one can conclude that the aid has not distorted competition. On the contrary, it has induced the entry of new ISPs, which in turn induced a moderate downward effect on prices. This negative impact on prices is more pronounced when the initial market is less competitive (more concentrated).

\section{Extensions and robustness checks}

In this section we explore extensions to the analysis conducted so far, which can shed further light on the mechanism at work, on the economics of broadband markets and how subsidies can affect them. 
First, we allow for spatial correlation among neighboring municipalities applying for aid as there might have been clustering in the application process. Second, we fully exploit the panel dimension of the data, by looking at the year-by-year effect of the state aid on coverage and entry. Third, we investigate how the amount of the aid influences the final outcomes and whether the returns are, possibly, nonlinear. Finally, we exploit the cross-sectional variability in the data documenting the heterogeneous effects of the aid as a function of few key characteristics of the target municipalities.

\subsection{Spatial correlation}

Some projects might have been coordinated among several municipalities, especially those that use the same MDF or collaborate in other dimensions. For instance in Lower Saxony, we observe that several schemes have been implemented by so-called "Samtgemeide," an administrative entity that associates several municipalities and executes administrative duties for them. Moreover, given the network nature of broadband infrastructure, the likelihood that one municipality applies for the aid might be influenced by the likelihood that neighboring municipalities also apply for the aid. Therefore, in a first robustness check, we take this spatial correlation into account when choosing the control group and measuring the effect of the treatment.

Specifically, to implement this step, we need to slightly modify the approach taken so far. Instead of estimating equation (2) using the pair of treated and control municipalities, we estimate the model at the municipality level were we include a spatial autoregressive term in the error term $M$, where $M$ is the spatial weighting matrix. In the same way as in the previous sections, we use the differences between 2015 (final year in sample) and 2010 (baseline year in sample). Thus, the spatial autoregressive version of equation (2) becomes equation (5).

$$
\Delta y_{i}=\alpha+\text { Treat }_{i}+\beta \Delta X_{i}+u_{i}, \quad \text { where } \quad u_{i}=\rho M \varepsilon_{i} .
$$

Subindex $i$ is the municipality, $\Delta y_{i}$ is the difference in the outcome variable between 2015 and 2010, and $\Delta X_{i}$ are the differences in the control variables. Treat $t_{i}$ is a dummy taking the value of one for the municipalities that used the aid and zero for the control municipalities. The matrix $M$ contains a set of weights with the $(i, j)$ element equal to 1 if municipalities $i$ and $j$ are neighbors and zero otherwise.

The average treatment effect is now captured by the coefficient of the variable Treat $_{i}$. Notice that, by running the regression on all municipalities without previously matching, we now have 3009 observations. Results are reported in Table (9). Comparing these findings to those reported in Table (5) and Table (6) we observe that the estimated coefficients are almost identical, the only exception being now significant negative effect of the aid on LTE entry. Thus, allowing for spatial clustering in the error terms does not qualitatively nor quantitatively change our findings. 
Table 9: Effect of the aid - Spatial autoregressive model.

\begin{tabular}{|c|c|c|c|c|c|c|c|c|}
\hline \multirow[t]{2}{*}{ Dependent variables: } & \multicolumn{3}{|c|}{$\Delta$ Coverage } & \multicolumn{5}{|c|}{$\Delta$ Entry in different technologies } \\
\hline & $\begin{array}{c}\mathbf{2 M B} / \mathbf{s} \\
(1)\end{array}$ & $\begin{array}{c}\mathbf{6 M B} / \mathbf{s} \\
(2)\end{array}$ & $\begin{array}{c}\mathbf{1 6} \mathrm{MB} / \mathbf{s} \\
(3)\end{array}$ & $\begin{array}{c}\text { All ISPs } \\
\text { (4) }\end{array}$ & $\begin{array}{l}\text { DSL } \\
(5)\end{array}$ & $\begin{array}{c}\text { Cable } \\
(6)\end{array}$ & $\begin{array}{l}\text { LTE } \\
(7)\end{array}$ & $\begin{array}{c}\text { FTTH } \\
(8)\end{array}$ \\
\hline State aid & $\begin{array}{c}20.19 * * * * \\
(1.00)\end{array}$ & $\begin{array}{c}27.50 * * * \\
(1.16)\end{array}$ & $\begin{array}{c}24.66 * * * \\
(1.15)\end{array}$ & $\begin{array}{c}0.19 * * * \\
(0.04)\end{array}$ & $\begin{array}{c}0.13^{* * * *} \\
(0.03)\end{array}$ & $\begin{array}{c}0.05^{* * * *} \\
(0.02)\end{array}$ & $\begin{array}{l}-0.06^{*} \\
(0.03)\end{array}$ & $\begin{array}{c}0.06 * * * \\
(0.01)\end{array}$ \\
\hline$\rho$ & $\begin{array}{l}-0.30 \\
(0.35)\end{array}$ & $\begin{array}{l}-0.30 \\
(0.35)\end{array}$ & $\begin{array}{l}-0.05 \\
(0.26)\end{array}$ & $\begin{array}{l}-0.07 \\
(0.20)\end{array}$ & $\begin{array}{c}-0.11 \\
(0.21)\end{array}$ & $\begin{array}{c}0.14 \\
(0.21)\end{array}$ & $\begin{array}{l}-0.13 \\
(0.24)\end{array}$ & $\begin{array}{l}-0.04 \\
(0.37)\end{array}$ \\
\hline$\Delta X$ & YES & YES & YES & YES & YES & YES & YES & YES \\
\hline Aver & 65.1 & 43.8 & 18.8 & 2.8 & 1.74 & 0.29 & 0.3 & 0.008 \\
\hline Average change & 25 & 35.8 & 42.2 & 2.6 & 1.6 & 0.21 & 2.88 & 0.077 \\
\hline Observations & 3009 & 3009 & 3009 & 3009 & 3009 & 3009 & 3009 & 3009 \\
\hline
\end{tabular}

\subsection{Effect of the state aid over time}

The analysis conducted in section 5 is based on the comparison of outcomes between the pre-treatment year (2010) and the last year in the sample (2015). This is partly justified by the fact that we do not have precise information on the local implementation of the state aid. Thus we chose to compare a clear pre-treatment period to a clear post-treatment period, as we are sure that by 2015 all projects were concluded. In order to better exploit the time variation in our panel, in this subsection we present the result of an empirical specification which exploits all years, keeping in mind that the aid was gradually rolled out between 2011 and 2014. Hence, we estimate an empirical model, reported in equation (6), where we include a set of yearly indicator variables to capture how the impact of the state aid built up over time, compared to the control municipalities (year 2010 being the baseline):

$$
\Delta y_{p t}=\alpha+\gamma_{1} \text { Year }_{p t}^{2011}+\gamma_{2} \text { Year }_{p t}^{2012}+\gamma_{3} \text { Year }_{p t}^{2013}+\gamma_{4} \text { Year }_{p t}^{2014}+\gamma_{5} \text { Year }_{p t}^{2015}+\lambda \Delta X_{p t}+\mu_{p}+\varepsilon_{p t} .
$$

The outcome variables $\Delta y$ are again the differences in the (yearly) change between matched municipalities of the coverage variables and of the entry variables. As in model (2), we include the set of control variables $\Delta X$ and the set of municipality-pair fixed effects $\mu$. Table 10 reports the results. The effect of the aid on coverage picks up quickly, as the first projects were implemented in 2011. This effect increases until 2013 when the vast majority of projects were concluded. The additional broadband availability due to the aid then remains fairly stable after that, indicating that control municipalities do not catch up rapidly.

Results for entry, on the other hand, show a lag in the response to the aid. This can be taken as an indication that it took additional entrants some time to be able to use the new infrastructure. Alternatively or additionally, this finding might indicate that firms waited to see whether the additional investment generated enough additional demand such that the market was attractive enough to enter. ISPs entered fast in DSL technology (which was the directly subsidised technology), whereas ISPs 
Table 10: Effect of the aid on coverage and entry. All years.

\begin{tabular}{|c|c|c|c|c|c|c|c|c|}
\hline \multirow[t]{2}{*}{ Dependent variable: } & \multicolumn{3}{|c|}{$\Delta$ Coverage } & \multicolumn{5}{|c|}{$\Delta$ Number of ISPs } \\
\hline & $\begin{array}{c}\mathbf{2 M B} / \mathbf{s} \\
(1)\end{array}$ & $\begin{array}{c}\mathbf{6 M B} / \mathbf{s} \\
(2)\end{array}$ & $\begin{array}{c}16 \mathrm{MB} / \mathrm{s} \\
(3)\end{array}$ & $\begin{array}{c}\text { All ISPs } \\
(4)\end{array}$ & $\begin{array}{c}\text { DSL } \\
(5)\end{array}$ & $\begin{array}{c}\text { Cable } \\
(6)\end{array}$ & $\begin{array}{c}\text { LTE } \\
(7)\end{array}$ & $\begin{array}{c}\text { FTTH } \\
(8)\end{array}$ \\
\hline Year $_{2011}$ & $\begin{array}{c}9.78 * * * \\
(0.81)\end{array}$ & $\begin{array}{c}12.95 * * * \\
(0.99)\end{array}$ & $\begin{array}{c}11.75 * * * \\
(0.98)\end{array}$ & $\begin{array}{c}0.08 * * \\
(0.04)\end{array}$ & $\begin{array}{c}0.04 \\
(0.02)\end{array}$ & $\begin{array}{l}-0.00 \\
(0.01)\end{array}$ & $\begin{array}{c}0.08 * * * \\
(0.03)\end{array}$ & $\begin{array}{c}0.00 \\
(0.00)\end{array}$ \\
\hline Year $_{2012}$ & $\begin{array}{c}14.78 * * * \\
(0.86)\end{array}$ & $\begin{array}{c}20.57 * * * \\
(1.10)\end{array}$ & $\begin{array}{c}19.15^{* * *} * \\
(1.11)\end{array}$ & $\begin{array}{c}0.12 * * * \\
(0.04)\end{array}$ & $\begin{array}{c}0.06 * * \\
(0.03)\end{array}$ & $\begin{array}{c}0.01 \\
(0.01)\end{array}$ & $\begin{array}{l}0.06^{*} \\
(0.04)\end{array}$ & $\begin{array}{c}0.00 \\
(0.00)\end{array}$ \\
\hline Year $_{2013}$ & $\begin{array}{c}15.57 * * * \\
(0.89)\end{array}$ & $\begin{array}{c}22.67 * * * \\
(1.13)\end{array}$ & $\begin{array}{c}20.33 * * * \\
(1.15)\end{array}$ & $\begin{array}{c}0.18 * * * \\
(0.05)\end{array}$ & $\begin{array}{c}0.15 * * * \\
(0.03)\end{array}$ & $\begin{array}{c}0.04 * * * \\
(0.02)\end{array}$ & $\begin{array}{l}-0.03 \\
(0.03)\end{array}$ & $\begin{array}{l}-0.00 \\
(0.01)\end{array}$ \\
\hline Year $_{2014}$ & $\begin{array}{c}15.14 * * * \\
(0.97)\end{array}$ & $\begin{array}{c}22.38 * * * \\
(1.24)\end{array}$ & $\begin{array}{c}21.41 * * * \\
(1.28)\end{array}$ & $\begin{array}{c}0.23 * * * \\
(0.05)\end{array}$ & $\begin{array}{c}0.15 * * * \\
(0.04)\end{array}$ & $\begin{array}{c}0.05 * * * \\
(0.02)\end{array}$ & $\begin{array}{l}-0.02 \\
(0.03)\end{array}$ & $\begin{array}{l}0.02 * * \\
(0.01)\end{array}$ \\
\hline Year $_{2015}$ & $\begin{array}{c}14.40 * * * \\
(1.00)\end{array}$ & $\begin{array}{c}21.14 * * * \\
\quad(1.25)\end{array}$ & $\begin{array}{c}20.56^{* * *} * \\
(1.29)\end{array}$ & $\begin{array}{c}0.21 * * * \\
(0.05)\end{array}$ & $\begin{array}{c}0.16 * * * \\
(0.04)\end{array}$ & $\begin{array}{c}0.06 * * * \\
(0.02)\end{array}$ & $\begin{array}{l}-0.02 \\
(0.04)\end{array}$ & $\begin{array}{c}0.05 * * * \\
(0.01)\end{array}$ \\
\hline$\Delta X$ & YES & YES & YES & YES & YES & YES & YES & YES \\
\hline$\mu$ & YES & YES & YES & YES & YES & YES & YES & YES \\
\hline $\mathrm{R}^{2}$ & 0.111 & 0.134 & 0.102 & 0.008 & 0.009 & 0.008 & 0.003 & 0.009 \\
\hline Observations & 6258 & 6258 & 6258 & 6258 & 6258 & 6258 & 6258 & 6258 \\
\hline
\end{tabular}

The dependent variables in columns (1) to (3) are the yearly changes of the differences between paired municipalities in the share of population that can access the internet at a speed of at least $2 \mathrm{Mbit} / \mathrm{s}, 6 \mathrm{Mib} / \mathrm{t}$ and $16 \mathrm{Mibt} / \mathrm{s}$. The dependent variables in columns (4) to (8) are the yearly changes of the differences between paired municipalities in the number of ISPs. Year 2011 - Year 2015 are indicator variables for the corresponding years. The vector of controls $\Delta X$ includes the changes in Population and Population ${ }^{2}$, Population density, Income, Work age, Unemployment, and Area firms and industry. $\mu$ is the municipality-pair fixed effect. The standard errors in parentheses are clustered at the level of the paired municipalities. ${ }^{*}, * *$, and $* * *$ denote significance at the 10,5 , and 1 percent level, respectively.

entered later in Cable and FTTH technologies. It might also be interesting to note how in LTE, after the initial boost in entry that we observe in 2011 and 2012, the untreated municipalities quickly closed the gap with the treated ones. These results have an intuitive explanation: while money can generate a long-lasting effect in fixed-line technologies, which require relatively large investments, this effect is short-lived in mobile technologies where companies can relatively quickly and cheaply build up the capacity to serve the entire market.

\subsection{Amount received}

In this subsection we investigate whether the amount of aid granted to the project has a differential impact on coverage and entry. We again slightly modify our main model (2) by introducing three interactions, based on the amount of the aid, of the Post treatment indicator. The three categories of the amount of the state aid are: $€ 50,000$ or less (small project); between $€ 50,000$ and $€ 100,000$ (mediumsized project), and above $€ 100,000$ (large project). The estimated model is reported in equation 7 below:

$$
\Delta y_{p t}=\alpha+\gamma_{1} \text { Post }_{p t}^{A i d \leq 50}+\gamma_{2} \text { Post }_{p t}^{50>A i d<100}+\gamma_{3} \text { Post }_{p t}^{A i d \geq 100}+\lambda \Delta X_{p t}+\mu_{p}+\varepsilon_{p t} .
$$


Results reported in Table (11) show that small projects have the smallest impact on coverage and no impact on entry. Medium-sized projects do not perform worse than large projects in terms of coverage, but large projects lead overall to more entry. It is also worth noticing that only large projects generate enough demand to trigger the entry of Cable and FTTH operators. A possible explanation for these results is that larger projects tend to be concentrated in larger municipalities where the positive effect on availability generates larger demand effects. This, in turn, attracts more entry. This point is related to the analysis that we present in the next section.

Table 11: Effectiveness of the Aid depending on Aid Amount.

\begin{tabular}{|c|c|c|c|c|c|c|c|c|}
\hline \multirow[t]{2}{*}{ Dependent variable: } & \multicolumn{3}{|c|}{$\Delta$ Coverage } & \multicolumn{5}{|c|}{$\Delta$ Entry in different tech } \\
\hline & $\begin{array}{c}\mathbf{2 M B} / \mathbf{s} \\
(1)\end{array}$ & $\begin{array}{c}\mathbf{6 M B} / \mathbf{s} \\
(2)\end{array}$ & $\begin{array}{c}\text { 16MB/s } \\
(3)\end{array}$ & $\begin{array}{c}\text { All ISPs } \\
(4)\end{array}$ & $\begin{array}{c}\text { DSL } \\
(5)\end{array}$ & $\begin{array}{c}\text { Cable } \\
(6)\end{array}$ & $\begin{array}{c}\text { LTE } \\
(7)\end{array}$ & $\begin{array}{c}\text { FTTH } \\
(8)\end{array}$ \\
\hline Post $^{A i d \leq 50}$ & $\begin{array}{c}8.52 * * * \\
(1.89)\end{array}$ & $\begin{array}{c}10.36 * * * \\
(2.34)\end{array}$ & $\begin{array}{c}7.65 * * * \\
(2.41)\end{array}$ & $\begin{array}{l}0.17 * \\
(0.10)\end{array}$ & $\begin{array}{c}0.00 \\
(0.07)\end{array}$ & $\begin{array}{c}0.01 \\
(0.04)\end{array}$ & $\begin{array}{c}-0.17 * * \\
(0.07)\end{array}$ & $\begin{array}{c}0.02 \\
(0.02)\end{array}$ \\
\hline Post ${ }^{50>A i d<100}$ & $\begin{array}{c}17.89 * * * \\
(1.91)\end{array}$ & $\begin{array}{c}25.20 * * * \\
(2.37)\end{array}$ & $\begin{array}{c}25.91 * * * \\
(2.44)\end{array}$ & $\begin{array}{c}0.23 * * \\
(0.10)\end{array}$ & $\begin{array}{c}0.20 * * * \\
(0.07)\end{array}$ & $\begin{array}{l}0.06^{*} \\
(0.04)\end{array}$ & $\begin{array}{l}-0.09 \\
(0.07)\end{array}$ & $\begin{array}{c}0.02 \\
(0.02)\end{array}$ \\
\hline $\operatorname{Post}^{A i d \geq 100}$ & $\begin{array}{c}15.90 * * * \\
(1.47)\end{array}$ & $\begin{array}{c}25.29 * * * \\
(1.83)\end{array}$ & $\begin{array}{c}25.22 * * * \\
(1.88)\end{array}$ & $\begin{array}{c}0.23 * * * \\
(0.08)\end{array}$ & $\begin{array}{c}0.23 * * * \\
(0.06)\end{array}$ & $\begin{array}{c}0.09 * * * \\
(0.03)\end{array}$ & $\begin{array}{c}0.12 * * \\
(0.06)\end{array}$ & $\begin{array}{c}0.08 * * * \\
(0.02)\end{array}$ \\
\hline$\Delta X$ & YES & YES & YES & YES & YES & YES & YES & YES \\
\hline$\mu$ & YES & YES & YES & YES & YES & YES & YES & YES \\
\hline $\mathrm{R}^{2}$ & 0.178 & 0.238 & 0.225 & 0.017 & 0.022 & 0.014 & 0.010 & 0.018 \\
\hline Observations & 2086 & 2086 & 2086 & 2086 & 2086 & 2086 & 2086 & 2086 \\
\hline
\end{tabular}

The dependent variables in columns (1) to (3) are the changes between 2015 and 2010 of the differences between paired municipalities in the share of population that can access the internet at a speed of at least $2 \mathrm{Mbit} / \mathrm{s}, 6 \mathrm{Mib} / \mathrm{t}$ and $16 \mathrm{Mibt} / \mathrm{s}$. The dependent variables in columns (4) to (8) are the changes between 2015 and 2010 of the differences between paired municipalities in the number of ISPs. Post ${ }^{\text {Aid } \leq 50}$, Post ${ }^{50>A i d<100}$, and Post ${ }^{A i d} \geq 100$ are indicator variables for the amount of state aid being within these 3 categories interacted with the Post indicator. The vector of controls $\Delta X$ includes the changes in Population and Population ${ }^{2}$, Population density, Income, Work age, Unemployment, and Area firms and industry. $\mu$ is the municipality-pair fixed effect. The standard errors in parentheses are clustered at the level of the paired municipalities. $*, * *$, and $* * *$ denote significance at the 10,5 , and 1 percent level, respectively.

\subsection{Other dimensions}

In this section, we explore different dimensions of potential heterogeneity of the found average effects. This heterogeneity analysis can help us to further understand the drivers of the observed effects as well as on their where the aid was mostly effective. To do so, we re-estimate our main model (2) on different sub-samples by splitting the whole (paired) sample at the median value along the following dimensions: i) initial internet coverage before the state aid; ii) distance to the MDF; and iii) degree of industrialisation.

The first dimension is based on DSL internet availability in the pre-treatment period. We thus compare municipalities with low DSL availability against those that had a relatively high DSL availability. The idea behind this split is twofold. On the one hand, it might pay off to make the investment on 
broadband infrastructure only if the municipalities are not too far behind. On the other hand, exactly for those municipalities, which are far behind in terms of availability, the aid is needed the most.

Second, pre-existing infrastructure conditions are a constraint for investment in broadband technologies. Specifically, it should be more expensive to improve the infrastructure for treated municipalities far away from the MDF when compared to municipalities relatively close. We therefore study whether there is a differential effect of the aid along this dimension. The third dimension of heterogeneity looks at the degree of industrialisation. This dimension is particularly relevant, as one of the main goals of the aid -especially the one offered by the federal states- was to provide a better broadband infrastructure that could also benefit small and medium-sized enterprises.

Table 12: Heterogeneity main sample.

\begin{tabular}{|c|c|c|c|c|c|c|c|c|}
\hline \multirow[t]{2}{*}{ Dependent variable: } & \multicolumn{3}{|c|}{$\Delta$ CCoverage } & \multicolumn{5}{|c|}{ 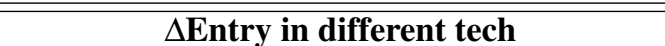 } \\
\hline & $\begin{array}{c}\mathbf{2 M B} / \mathbf{s} \\
(1)\end{array}$ & $\begin{array}{c}\mathbf{6 M B} / \mathbf{s} \\
(2)\end{array}$ & $\begin{array}{c}16 \mathrm{MB} / \mathrm{s} \\
(3)\end{array}$ & $\begin{array}{l}\text { All ISPs } \\
(4)\end{array}$ & $\begin{array}{c}\text { DSL } \\
(5)\end{array}$ & $\begin{array}{c}\text { Cable } \\
(6)\end{array}$ & $\begin{array}{c}\text { LTE } \\
(7)\end{array}$ & $\begin{array}{c}\text { FTTH } \\
(8)\end{array}$ \\
\hline \multicolumn{9}{|c|}{ Below median DSL 2008} \\
\hline Post & $\begin{array}{c}15.70 * * * \\
(1.53)\end{array}$ & $\begin{array}{c}21.56^{* * * *} \\
(1.82)\end{array}$ & $\begin{array}{c}19.60 * * * \\
(1.85)\end{array}$ & $\begin{array}{c}0.43 * * * \\
(0.07)\end{array}$ & $\begin{array}{c}0.19 * * * \\
(0.06)\end{array}$ & $\begin{array}{c}0.04 \\
(0.03)\end{array}$ & $\begin{array}{c}-0.12 * * \\
(0.05)\end{array}$ & $\begin{array}{l}0.03^{*} \\
(0.02)\end{array}$ \\
\hline \multicolumn{9}{|c|}{ Above median DSL 2008} \\
\hline Post & $\begin{array}{c}13.14 * * * \\
(1.29)\end{array}$ & $\begin{array}{c}20.73 * * * \\
(1.71)\end{array}$ & $\begin{array}{c}21.49 * * * \\
(1.81)\end{array}$ & $\begin{array}{c}0.01 \\
(0.07)\end{array}$ & $\begin{array}{l}0.13 * * \\
(0.05)\end{array}$ & $\begin{array}{c}0.08 * * * \\
(0.03)\end{array}$ & $\begin{array}{c}0.09 \\
(0.06)\end{array}$ & $\begin{array}{c}0.06 * * * \\
(0.02)\end{array}$ \\
\hline $\begin{array}{l}\text { Close to the MDF } \\
\text { Post }\end{array}$ & $\begin{array}{c}4.26 * * * \\
(0.95)\end{array}$ & $\begin{array}{l}9.10 * * * \\
(1.34)\end{array}$ & $\begin{array}{c}13.59 * * * \\
(1.57)\end{array}$ & $\begin{array}{l}0.28 * * * \\
(0.07)\end{array}$ & $\begin{array}{c}0.33 * * * \\
(0.05)\end{array}$ & $\begin{array}{c}0.12 * * * \\
(0.03)\end{array}$ & $\begin{array}{c}0.03 \\
(0.06)\end{array}$ & $\begin{array}{c}0.09 * * * \\
(0.02)\end{array}$ \\
\hline $\begin{array}{l}\text { Far from the } M D F \\
\text { Post }\end{array}$ & $\begin{array}{c}24.22 * * * \\
(1.62)\end{array}$ & $\begin{array}{c}32.80 * * * \\
(1.96)\end{array}$ & $\begin{array}{c}27.29 * * * \\
(1.99)\end{array}$ & $\begin{array}{c}0.15^{* *} * \\
(0.07) \\
\end{array}$ & $\begin{array}{l}-0.01 \\
(0.05)\end{array}$ & $\begin{array}{c}0.01 \\
(0.03)\end{array}$ & $\begin{array}{l}-0.06 \\
(0.05)\end{array}$ & $\begin{array}{c}0.01 \\
(0.02)\end{array}$ \\
\hline \multicolumn{9}{|l|}{ Below median industry } \\
\hline Post & $\begin{array}{c}14.90 * * * \\
(1.38)\end{array}$ & $\begin{array}{c}20.65^{* * * *} \\
(1.73)\end{array}$ & $\begin{array}{c}20.97 * * * \\
(1.76)\end{array}$ & $\begin{array}{c}0.43 * * * \\
(0.07)\end{array}$ & $\begin{array}{c}0.35 * * * \\
(0.05)\end{array}$ & $\begin{array}{c}0.11 * * * \\
(0.03)\end{array}$ & $\begin{array}{c}-0.12 * * \\
(0.05)\end{array}$ & $\begin{array}{c}0.06 * * * \\
(0.02)\end{array}$ \\
\hline \multicolumn{9}{|l|}{ Above median Industry } \\
\hline Post & $\begin{array}{c}13.80 * * * \\
(1.44)\end{array}$ & $\begin{array}{c}21.74 * * * \\
(1.80)\end{array}$ & $\begin{array}{c}20.05^{* * * *} \\
(1.90)\end{array}$ & $\begin{array}{l}-0.05 \\
(0.08)\end{array}$ & $\begin{array}{l}-0.07 \\
(0.06)\end{array}$ & $\begin{array}{c}0.01 \\
(0.03) \\
\end{array}$ & $\begin{array}{l}0.11 * \\
(0.06)\end{array}$ & $\begin{array}{c}0.03 \\
(0.02)\end{array}$ \\
\hline
\end{tabular}

The dependent variables in columns (1) to (3) are the changes between 2015 and 2010 of the differences between paired municipalities in the share of population that can access the internet at a speed of at least $2 \mathrm{Mbit} / \mathrm{s}, 6 \mathrm{Mib} / \mathrm{t}$ and $16 \mathrm{Mibt} / \mathrm{s}$. The dependent variables in columns (4) to (8) are the changes between 2015 and 2010 of the differences between paired municipalities in the number of ISPs. Post is an indicator that takes value 1 in 2015 (post-treatment) and 0 in 2010 (pre-treatment). All regressions include the vector of controls that we employed in previous regressions: $\Delta X$ includes the changes in Population and Population ${ }^{2}$, Population density, Income, Work age, Unemployment, and Area firms and industry. $\mu$ is the municipality-pair fixed effect. The standard errors in parentheses are clustered at the level of the paired municipalities. *, **, and $* * *$ denote significance at the 10,5 , and 1 percent level, respectively.

We obtain six subsamples: the paired municipalities above/below median coverage, the paired municipalities above/below median distance to the MDF, and the paired municipalities above/below the median level of industrial presence. Table 12 reports the results. Each cell represents one regression; for the sake of space, we only report the coefficient estimate for the treatment effect within that particular 
sample. The effect of the aid on availability is slightly larger in municipalities with a below median DSL penetration in 2010, with above median industrialisation structure, and farther from the MDF. Almost all these results are particularly encouraging, as it seems that the aid was mostly effective in spurring investment where it was mostly needed.

The effects on entry are also heterogeneous. For DSL, the effects are significantly larger in areas not too far from the MDF. This would suggest that the costs of entering the DSL markets also for additional entrants are potentially related to rurality and distance to the MDF. For cable, the effects are larger in rural areas, in areas with below median industrialisation, as well as in municipalities that are not too far from the MDF. Notice that, similarly to the results discussed in the previous section, the positive effect of the aid on entry in the cable and FTTH technology are exclusively observed in municipalities that had a higher than median DSL in 2008. These are again mostly larger and more attractive municipalities where the demand-expansion effect of the aid might make entry for all technologies more attractive.

\section{Conclusions}

The analysis provided in this paper shows that the state aid schemes implemented in Lower Saxony and Bavaria to provide incentives to private operators to offer broadband services in rural areas have been successful. First, the schemes were effective in increasing coverage within the aid-implementing municipalities relative to comparable municipalities in terms of demographic and technological characteristics. Specifically, we measure an additional increase in broadband coverage due to the aid ranging between over $14 \%$ for connections at $2 \mathrm{Mbit} / \mathrm{s}$ to around $21 \%$ for connections at speeds larger than 16 Mbit/s.

Second, and more important for this study on state aid control, we find that the implemented schemes did not impair competition. On the contrary, we find that the number of ISPs competing in a local market has significantly increased in the treated municipalities when compared to the control group by ca. $8 \%$ over the common trend. This is true not only for the DSL markets -which were most subsidised- but also for other technologies such as cable and fiber. Third, the impact of this additional entrance on prices is negative, although the economic impact is small. However, the impact of aid on entry -as well as the impact that this additional aid-induced entry had on prices- is highest when the market was initially more concentrated. In other words, where the literature on entry predicts that entry could have a meaningful impact on competition and competitive outcomes, this is indeed the case in our study.

Going beyond these average effects, we also show that there is heterogeneity in the effectiveness of the aid, as well as its implications on competition. Specifically, we find that the aid was mostly effective where it was mostly needed: in municipalities with low DSL coverage pre-aid and with a large distance to the MDF. Moreover, we find that the highest marginal effect of the aid is generally observed for grants of medium size (between $€ 50,000$ and $€ 100,000$ ). 
To our knowledge, this paper is the first to provide a full quantitative ex-post analysis of EU state aid control. Thus, it represents a first step that lays out a conceptual framework to assess an important and, to date, still under-researched policy area with the aim of stimulating further academic research. Indeed, while there is substantial empirical research assessing the effectiveness of subsidies, the evidence on their impact on competition - a major dimension under control of the European Commission in its state aid control framework - is scarce.

Finally, while we obtained detailed data compared to other studies, there are still interesting issues which could not be addressed in the current study because of a lack of information. For instance, we do not know which technology was subsidised in each single municipality, which operator received the aid and when, as well as what exact conditions of open access were imposed on the aid-receivers. For future analysis, we believe that the EC should impose the involved parties to be much more transparent in providing the necessary data that allow understanding how public money has been spent.

\section{References}

Aghion, Philippe, Jing Cai, Mathias Dewatripont, Luosha Du, Ann Harrison, and Patrick Legros. 2015. "Industrial policy and competition.” American Economic Journal: Macroeconomics, 7(4): 132.

Aguzzoni, Luca, Elena Argentesi, Lorenzo Ciari, Tomaso Duso, and Massimo Tognoni. 2016. "Ex Post Merger Evaluation in the UK Retail Market for Books." The Journal of Industrial Economics, 64(1): 170-200.

Akerman, Anders, Ingvil Gaarder, and Magne Mogstad. 2015. "The skill complementarity of broadband internet." The Quarterly Journal of Economics, 130(4): 1781-1824.

Becker, Sascha O, Peter H Egger, and Maximilian von Ehrlich. 2018. "Effects of EU regional policy: 1989-2013.” Regional Science and Urban Economics, 69: 143-152.

Bresnahan, Timothy F, and Peter C Reiss. 1991. "Entry and Competition in Concentrated Markets." The Journal of Political Economy, 99(5): 977-1009.

Briglauer, Wolfgang, Niklas S Dürr, Oliver Falck, and Kai Hüschelrath. 2019. "Does state aid for broadband deployment in rural areas close the digital and economic divide?" Information Economics and Policy.

Cerqua, Augusto, and Guido Pellegrini. 2014. "Do subsidies to private capital boost firms' growth? A multiple regression discontinuity design approach.” Journal of Public Economics, 109: 114-126.

Cohen, Andrew M, and Michael J Mazzeo. 2007. "Market structure and competition among retail depository institutions." The Review of Economics and Statistics, 89(1): 60-74. 
Criscuolo, Chiara, Ralf Martin, Henry G Overman, and John Van Reenen. 2019. "Some causal effects of an industrial policy." American Economic Review, 109(1): 48-85.

Czernich, Nina, Oliver Falck, Tobias Kretschmer, and Ludger Woessmann. 2011. "Broadband infrastructure and economic growth." The Economic Journal, 121(552): 505-532.

Dehejia, Rajeev H, and Sadek Wahba. 2002. "Propensity score-matching methods for nonexperimental causal studies." Review of Economics and statistics, 84(1): 151-161.

European Commission. 2009. "Community Guidelines for the application of State aid rules in relation to rapid deployment of broadband networks." Official Journal of the European Union, C $235 / 7$.

https://eur-lex.europa.eu/legal-content/EN/TXT/?uri=

CELEX3A52013XC0126280129

Falck, Oliver, Robert Gold, and Stephan Heblich. 2014. "E-lections: Voting Behavior and the Internet." The American Economic Review, 104(7): 2238-2265.

Fan, Ying, and Mo Xiao. 2015. "Competition and subsidies in the deregulated US local telephone industry." the RAND Journal of Economics, 46(4): 751-776.

Flynn, Leo. 2016. EU Competition Law, Volume 4: State Aid. Claeys \& Casteels Law Publishing.

Friederiszick, Hans, Ela Glowicka, Linda Gratz, Simone Lunenburger, and Andreas Rosenfeld. 2018. "Ex Post State Aid Evaluation in Environmental Aid." Eur. St. Aid LQ, 509.

FTTHCouncil. 2017. "The Cost of Meeting Europe's Future Network Needs." FTTH Council Europe. Available at: https://www.ftthcouncil.eu/documents/Reports/2017/FTTH\%20Council\% 20Cost\%20Model\%202017_final.pdf

Genakos, Christos, Tommaso Valletti, and Frank Verboven. 2018. "Evaluating market consolidation in mobile communications." Economic Policy, 33(93): 45-100.

Gómez-Barroso, José Luis, and Claudio Feijóo. 2012. "Volition versus feasibility: state aid when aid is looked upon favourably: the broadband example." European Journal of Law and Economics, 34(2): 347-364.

Greenstein, Shane. 2020. "The Basic Economics of Internet Infrastructure." Journal of Economic Perspectives, 34(2): 192-214.

Heckman, James J, Hidehiko Ichimura, and Petra E Todd. 1997. "Matching as an econometric evaluation estimator: Evidence from evaluating a job training programme.” The Review of Economic Studies, 64(4): 605-654. 
Heckman, James J, Hidehiko Ichimura, and Petra Todd. 1998. "Matching as an econometric evaluation estimator." The Review of Economic Studies, 65(2): 261-294.

Heidhues, Paul, and Rainer Nitsche. 2006. "Comments on state aid reform-some implications of an effects-based approach.” European State Aid Law Quarterly, 5(1): 23-34.

Heim, Sven, Kai Hüschelrath, Philipp Schmidt-Dengler, and Maurizio Strazzeri. 2017. "The impact of state aid on the survival and financial viability of aided firms." European Economic Review, 100: 193-214.

Hosken, Daniel S, Luke Olson, and Loren Smith. 2015. "Do retail mergers affect competition? Evidence from grocery retailing." Federal Trade Commission, mimeo.

Kline, Patrick M, and Enrico Moretti. 2014a. "Local economic development, agglomeration economies, and the big push: 100 years of evidence from the Tennessee Valley Authority." Quarterly Journal of Economics, 129(1): 275-331.

Kline, Patrick M, and Enrico Moretti. 2014b. "People, places and public policy: Some simple welfare economics of local economic development programs." Annual Review of Economics, 6: 629662.

Munoz de Juan, Maria. 2018. “Monitoring of state aid.” Eur. St. Aid LQ, 483.

Nardotto, Mattia, Tommaso Valletti, and Frank Verboven. 2015. "Unbundling the incumbent: Evidence from UK broadband.” Journal of the European Economic Association, 13(2): 330-362.

Nevo, Aviv, John L Turner, and Jonathan W Williams. 2016. "Usage-Based Pricing and Demand for Residential Broadband." Econometrica, 84(2): 411-443.

Nitsche, Rainer, Paul Heidhues, et al. 2006. "Study on methods to analyse the impact of State aid on competition." Directorate General Economic and Financial Affairs (DG ECFIN), European Commission.

OECD. 2001. "Understanding the Digital Divide.” OECD. Available at: http://www.oecd.org/ internet/ieconomy/1888451.pdf.

Riley, Shawn J, Stephen D DeGloria, and Robert Elliot. 1999. "Index that quantifies topographic heterogeneity." intermountain Journal of sciences, 5(1-4): 23-27.

Robins, Nicole, and Hannes Geldof. 2018. "Ex post assessment of the impact of state aid on competition." Eur. St. Aid LQ, 494.

Sergant, Ilona, and Patrick Van Cayseele. 2019. "Financial Constraints: State Aid to the Rescue? Empirical Evidence from Belgian Firm-Level Data." Journal of Industry, Competition and Trade, 19(1): 33-67. 
Szücs, Florian. 2020. "Do research subsidies crowd out private R\&D of large firms? Evidence from European Framework Programmes.” Research Policy, 49(3): 103923.

Toivanen, Otto, and Michael Waterson. 2005. "Market Structure and Entry: Where's the Beef?" RAND Journal of Economics, 36(5): 547-561.

Xiao, Mo, and Peter F Orazem. 2011. "Does the fourth entrant make any difference?: Entry and competition in the early US broadband market." International Journal of Industrial Organization, 29(5): 547-561. 